Review Article

\title{
Molecular Markers for Prostate Cancer in Formalin-Fixed Paraffin-Embedded Tissues
}

\author{
Tamara Sequeiros, Marta García, Melania Montes, Mireia Oliván, Marina Rigau, \\ Eva Colás, Inés de Torres, Juan Morote, Jaume Reventós, and Andreas Doll
}

Research Unit in Biomedicine and Translational Oncology, Research Institute Vall Hebron University Hospital (VHIR) and
Universitat Autònoma de Barcelona (UAB), 08035 Barcelona, Spain

Correspondence should be addressed to Andreas Doll; andreas.doll@vhir.org

Received 29 August 2013; Accepted 10 October 2013

Academic Editor: Renato Franco

Copyright (C) 2013 Tamara Sequeiros et al. This is an open access article distributed under the Creative Commons Attribution License, which permits unrestricted use, distribution, and reproduction in any medium, provided the original work is properly cited.

\begin{abstract}
Prostate cancer $(\mathrm{PCa})$ is the most frequently diagnosed type of cancer in developed countries. The decisive method of diagnosis is based on the results of biopsies, morphologically evaluated to determine the presence or absence of cancer. Although this approach leads to a confident diagnosis in most cases, it can be improved by using the molecular markers present in the tissue. Both miRNAs and proteins are considered excellent candidates for biomarkers in formalin-fixed paraffin-embedded (FFPE) tissues, due to their stability over long periods of time. In the last few years, a concerted effort has been made to develop the necessary tools for their reliable measurement in these types of samples. Furthermore, the use of these kinds of markers may also help in establishing tumor grade and aggressiveness, as well as predicting the possible outcomes in each particular case for the different treatments available. This would aid clinicians in the decision-making process. In this review, we attempt to summarize and discuss the potential use of microRNA and protein profiles in FFPE tissue samples as markers to better predict PCa diagnosis, progression, and response to therapy.
\end{abstract}

\section{Introduction}

Prostate cancer (PCa) is the most commonly diagnosed cancer and the second leading cause of cancer death among European and American men [1]. The current screening method to diagnose PCa is based on a measurement of serum prostate specific antigen (PSA) levels and a digital rectal examination (DRE), while a decisive diagnosis is based on the results of transrectal, ultrasound-guided prostate biopsies (PBs).

The introduction of the serum PSA test in the late 1980s has led to an increase in the detection of new PCa cases [2]. However, serum PSA has some well-recognized limitations; it lacks diagnostic specificity and prognostic value, and it leads to a high rate of false positives [3]. This lack of specificity is associated with an increased percentage of negative $\mathrm{PB}$ and the overdiagnosis of many indolent tumors, resulting in the overtreatment of patients. Consequently, there exists urgent need to find more effective and specific PCa detection markers.

The management of diagnosed PCa is crucially dependent on the presentation of the disease [4]. By nature, PCa progresses slowly and can be treated effectively with early detection by radical prostatectomy (RP); however, patients diagnosed with high risk PCa or metastatic disease have a $50 \%$ risk of disease progression 5 years after surgery [5]. For this reason, these patients are provided with closer follow-up and more intensive treatment by adjuvant therapy to avoid local and distant disease, usually radiation therapy (RT) and androgen deprivation therapy (ADT) [6]. To help clinicians choose the best treatment approach for each particular case, it is critical to identify markers that distinguish indolent cases of PCa from those that will progress and metastasize.

In the past few years, thanks to current advancements in proteomics, RNA and DNA microarrays, immunohistochemical (IHC) staining, and other biotechnologies, new 
approaches have been applied to identify and validate more accurate diagnostic and prognostic biomarkers in tissue samples [7].

\section{Biomarker Discovery in FFPE Tissue}

Although fresh-frozen (FF) tissue remains the gold standard for extraction and large-scale profiling in genomic and proteomic studies, analyzing molecules in formalinfixed paraffin-embedded (FFPE) tissues is gaining increased interest. This interest is primarily driven by the fact that the process of creating FFPE tissue is the most common technique used by clinical and/or research pathologists for tissue processing, evaluation, diagnostics, immunoanalysis, preservation, and archiving. These archived FFPE tissues may provide wealth of information when used in retrospective molecular studies that focus on molecular profiling and biomarker research [8]. It is true that the quantity and quality of proteins, nucleic acids, and metabolites obtained from FFPE tissues are inferior to the extraction efficiency obtained from FF tissues $[8,9]$. However, the use of FFPE samples in molecular expression analysis studies presents some great advantages. For example, these types of samples are available and readily accessible in vast quantities. The cost associated with their storage is low, as well, and the significant association between pathological and clinical annotations makes FFPE tissue an attractive specimen for biomarker discovery. Nevertheless, when working with nucleic acids, FFPE samples present some drawbacks as RNA and DNA can be degraded and modified by the fixation process and, independently, degraded with time.

In the late 1990s, tissue microarray (TMA) technology revolutionized the investigation of potential prognostic and predictive biomarkers $[10,11]$. TMAs are commonly used to study tissue morphology, the expression of proteins or genes, and chromosomal aberrations using IHC and in situ hybridization (ISH) [11]. The combination of TMAs and clinically annotated samples is useful when studying panels of biomarkers under identical experimental conditions, as well as in the development of prognostic or predictive models for patient outcome [12]. Despite these considerable advantages, the conventional construction of TMAs is often meticulous, laborious, and time consuming. Recently, Zlobec et al. [11] proposed the term, next-generation tissue microarrays (ngTMAs), to define a combination of cutting-edge digital pathology, automated TMAs, and histopathological expertise, which would ultimately benefit the further optimization of biomarker research.

The purpose of this review is to examine the potential use of previously described, small noncoding RNAs, microRNAs, and protein profiles as markers that may help predict $\mathrm{PCa}$ diagnosis, progression, and response to therapy in prostate FFPE specimens. To date, only a few of these markers have achieved widespread clinical use.

2.1. MicroRNAs as Biomarkers in Prostate FFPE Samples. In recent years, evidence has accumulated showing that small noncoding RNAs are used in a conserved manner to regulate key developmental events. At least four classes of regulatory, small noncoding RNAs have been described, including microRNAs (miRNAs), short interfering RNAs (siRNA), repeat-associated small interfering RNAs (rasiRNAs), and piwi-interacting RNAs (piRNAs) [13]. Among these small RNAs, the miRNAs, which are the most phylogenetically conserved, posttranscriptionally regulate the genes involved in several physiological and pathological processes [14-16]. Therefore, their aberrant expression results in a variety of pathological events, such as cancer $[17,18]$. Generally, the importance of miRNAs in cancer is emphasized by the fact that around $50 \%$ of all miRNA genes are positioned in socalled fragile sites, genomic regions that are associated with repeated changes that occur in cancer $[18,19]$. Moreover, miRNAs are attractive candidates as multifunctional regulators of disease progression, because one miRNA can regulate an entire set of genes [20]. It is believed that miRNAs regulate about $30 \%$ of all protein-coding human genes [21-23]. Finally, several miRNAs and their targets have been found to be aberrantly expressed in PCa [18, 24-26]. For that reason, certain miRNAs are now considered valuable biomarkers for diagnosis, prognosis, and the classification of PCa [27, 28].

Furthermore, miRNAs present several advantageous features that make them a source of potential cancer biomarkers in FFPE tissues. First, unlike other nucleic acids, miRNAs are potentially more robust. Due to their small size and protection by the RISC complex, which makes them resistant to endogenous RNase activity, they are less affected by FFPEdependent degradation [29-32]. Second, their expression levels can be measured reliably in FFPE tissue samples, and only minute quantities of RNA are needed to establish their expression using reliable, quantitative PCR amplification strategies [33]. Third, miRNA expression profiles are not dependent on the preservation of the specimen's architecture and cellular arrangement or the degree of cellular degeneration [29]. Finally, a good correlation between the expression profiles of FF and FFPE samples with miRNAs and messenger RNAs (mRNAs) has been observed and reported in liver [34], glioblastoma [35], and PCa specimens [36]. Therefore, the expression profiling of miRNAs is an accurate and robust method for the molecular analysis of archived clinical specimens, which potentially extends the use of miRNAs as new diagnostic, prognostic, and treatment response biomarkers [30]. Currently, high-throughput screening methods, such as microarrays, can be applied to detect miRNAs in prostate FFPE tissues; however, quantitative real-time reverse-transcription PCR (qRT-PCR) is still one of the most common high sensitivity and specificity methods used to detect low miRNA levels [37].

In recent years, specific miRNA signatures for PCa have been described in several studies [27, 28, 38-44], suggesting that miRNAs or miRNA profiles can be used as diagnostic and prognostic markers for this disease [45]. These markers exhibit distinct abilities to detect PCa and to predict disease course. Some of them are listed in Table 1 and discussed below. 
TABLE 1: miRNAs as PCa biomarkers in FFPE tissue.

\begin{tabular}{|c|c|c|}
\hline miRNA & Clinical significance & References \\
\hline Let-7 family & Diagnosis, prognosis $(\downarrow)$ & {$[45,52]$} \\
\hline $\operatorname{miR}-17$ & Diagnosis, prognosis $(\downarrow)$ & {$[154,155]$} \\
\hline miR-19a & Diagnosis & [156] \\
\hline $\mathrm{miR}-20 \mathrm{a} / \mathrm{b}$ & Diagnosis & {$[154]$} \\
\hline miR-21 & Prognosis $(\uparrow)$, treatment outcome & [157] \\
\hline miR-25 & Diagnosis & {$[156]$} \\
\hline miR-26a & Diagnosis $(\downarrow)$ & {$[21]$} \\
\hline miR-29a & Diagnosis $(\downarrow)$ & {$[21,158]$} \\
\hline miR-29b & Diagnosis $(\downarrow)$ & [159] \\
\hline miR-31-5p & Diagnosis $(\downarrow)$ & {$[66]$} \\
\hline miR-30d & Diagnosis $(\uparrow)$ & {$[21]$} \\
\hline miR-34a & Diagnosis $(\downarrow)$ & {$[21,160]$} \\
\hline $\operatorname{miR}-34 c-5 p$ & Diagnosis $(\downarrow)$ & {$[66]$} \\
\hline miR-93 & Diagnosis & {$[154]$} \\
\hline miR-101 & Diagnosis & {$[154]$} \\
\hline miR-106a & Diagnosis & {$[154]$} \\
\hline miR-125b & Diagnosis $(\uparrow)$ & {$[25]$} \\
\hline miR-126 & Diagnosis $(\downarrow)$ & {$[21]$} \\
\hline miR-132 & Prognosis $(\downarrow)$, treatment outcome & {$[161]$} \\
\hline miR-141 & Diagnosis & {$[154]$} \\
\hline miR-143 & Diagnosis, prognosis $(\downarrow)$ & {$[43,51,156]$} \\
\hline miR-145 & Diagnosis, prognosis $(\downarrow)$ & {$[43,49-51,154,162]$} \\
\hline miR-146a/b-5p & Diagnosis, prognosis $(\downarrow)$ & {$[163]$} \\
\hline miR-183-96-182 cluster & Diagnosis, prognosis & {$[56,59,66,154,164]$} \\
\hline miR-187 & Diagnosis & {$[156]$} \\
\hline miR-195 & Diagnosis $(\downarrow)$ & {$[21]$} \\
\hline miR-200a & Treatment outcome & {$[56]$} \\
\hline miR-203 & Diagnosis, prognosis $(\downarrow)$ & {$[164]$} \\
\hline miR-214 & Diagnosis & {$[154]$} \\
\hline miR-221 & Diagnosis, prognosis $(\downarrow)$, treatment outcome & {$[55,154]$} \\
\hline miR-222 & Diagnosis & [154] \\
\hline miR-342-3p & Diagnosis $(\uparrow)$ & [21] \\
\hline miR-375 & Diagnosis $(\uparrow)$ & {$[43,154]$} \\
\hline miR-519d & Prognosis $(\uparrow)$, treatment outcome & [67] \\
\hline miR-616 & Diagnosis $(\uparrow)$ & {$[165]$} \\
\hline miR-622 & Diagnosis $(\uparrow)$ & {$[21]$} \\
\hline miR-647 & Prognosis $(\downarrow)$, treatment outcome & {$[67]$} \\
\hline miR-720 & Diagnosis & {$[154]$} \\
\hline miR-768-3p & Diagnosis & [154] \\
\hline miR-1256 & Diagnosis $(\downarrow)$ & {$[158]$} \\
\hline
\end{tabular}

Arrows indicate the sense of deregulation: $(\uparrow)$ : upregulation; $(\downarrow)$ : downregulation in PCa versus normal tissues or low risk versus high risk PCa.

The downregulation of miRNAs is the most frequently observed phenomenon in cancer, suggesting that they function as tumor suppressor genes [46]. Loss of mir-145 expression has been reported in many human cancers $[47,48]$, including PCa [49]. The downregulation of miR-145 has been associated with an aggressive phenotype and poor prognosis in PCa [50]. Peng et al. [51] reported that in FFPE specimens the downregulation of miR-143 and miR-145 was negatively correlated to bone metastasis, Gleason score, and the level of free PSA in primary PCa. Recently, Suh et al. [49] documented that the downregulation of miR-145 in PCa could play a role in cancer initiation, and that the mechanism for its regulation is mediated by DNA methylation and p53 mutation pathways (a protein marker discussed later in this review).

Some of the most frequently mentioned miRNAs that appear downregulated in PCa are members of the let-7 family [45]. This family appears to play a key role in the recurrence 
and progression of PCa by maintaining and regulating the molecular features of cancer stem cells (CSCs) or cancer stem-like cells [52]. Loss of the let-7 family has been found in human PCa FFPE tissue specimens, especially in higher Gleason grade tumors, and it has been strongly linked to the acquisition of epithelial to mesenchymal transition (EMT) phenotype [52] and to the negative regulation of RAS protein [53]. These data suggest that inducing the re-expression of miRNAs from the let-7 family could represent a new therapeutic approach for aggressive PCa. A very recent report [45] identified let-7b as an independent prognostic marker for biochemical recurrence (BCR) and clinical failure in highrisk PCa. Furthermore, alterations in the expression profile of miR-let7c, miR-100, and miR-218 have been described during the progression from localized to metastatic PCa $[46,54]$.

MiR-221 is also a strongly downregulated miRNA in $\mathrm{PCa}$, as clearly confirmed by several miRNA expression studies of PCa [28, 39, 40, 55]. Spahn et al. [55] identified a miRNA profile, (including miR-221, which has been related to metastasis) comparing the miRNA expression patterns in primary carcinoma and lymph node metastatic tissue. Moreover, the downregulation of miR-221 was associated with clinicopathological parameters, including Gleason score and clinical recurrence. These results suggest that miR-221 could be a novel prognostic indicator in high risk $\mathrm{PCa}$, and it could be clinically useful for advising additional therapeutic strategies to PCa patients.

MiR-200a, a member of the miR-200 family, has been implicated in the regulation of EMT and postulated to be hijacked by cancer cells during tumor metastasis [56]. Barron et al. [56] showed downregulation of miR-200a in PCa tissue from men who relapsed compared to those who did not. Moreover, they also observed reduced expression of the other two miRNAs in the miR-200a cluster (miR-200b and miR429), suggesting that those miRNAs are jointly repressed in patients suffering from relapsing disease. Although miR200a did not demonstrate adequate sensitivity or specificity to serve as a reliable relapse predictor, surely it could be considered a valuable addition to a panel of biomarkers. These findings are supported by other recent studies, which link miR-200 family members to PCa progression [52].

On the other hand, overexpressed miRNAs in cancer have occasionally been observed $[38,57]$. These may function as oncogenes and promote cancer development by negatively regulating tumor suppressor genes and/or genes that control cell differentiation or apoptosis.

The overexpression of miR-183, miR-96 and miR-182, individually or as a cluster, has been reported in cancer [58], including PCa $[59,60]$. In particular, mir-182-5p has been described as an oncogene in several cancers [61-64]. Its expression was found to be significantly higher in PCa tissues compared to normal prostate tissues [59, 60, 65], and it has been associated with shorter overall survival in PCa patients. Recently, Tsuchiyama et al. [66] demonstrated that in FFPE tissue samples, the expressions of miR-182-5p, as well as mir31-5p and mir-205-5p, were significantly higher in high grade tumors compared to those of intermediate grade. This would suggest that miR-182-5p is a useful marker for high grade PCa.
Long et al. [67], analyzing the expression profiles of 70 archived FFPE tumor specimens, showed that miR-519d and miR-647 could serve as biomarkers to discriminate between patients with and without BCR following RP. MiR-519d was positively associated with the risk of BCR, while miR-647 presented a negative association.

2.2. Protein Biomarkers in Prostate FFPE Samples. The diagnosis of PCa in histopathological specimens is based mainly on a combination of architectural and cellular atypia, and in a vast majority of cases, a confident diagnosis can be made based on morphology alone. However, in some cases, the morphological findings are insufficient for a conclusive diagnosis, either because the atypia is too mild or the atypical focus is too small. The diagnostic accuracy of a morphologybased diagnosis can be improved in some cases by IHC that uses one or several biomarkers, either on consecutive sections or by the use of stained marker cocktails [68].

The detection of protein biomarkers by IHC presents multiple advantages, due to their high stability in FFPE tissues compared to other molecules. Multiple reports have shown that proteins and even protein modifications, such as phosphorylations, are maintained and can be determined years later by IHC [69]. In the last two decades, the ability to detect antigens in tissue sections has improved dramatically, mainly by countering the deleterious effects of formaldehyde with antigen retrieval and increasing the sensitivity of the detection systems [70]. From a clinical perspective, the IHC method correlates molecular detail to histopathological changes found in patient-derived tissues. Consequently, IHC is an excellent, simple, and effective technique for the detection of molecular biomarkers in FFPE samples. Currently, the IHC method is considered one of the pillars of modern diagnostic pathology and a fundamental research tool in both pathology and translational research laboratories [71]. Some of the protein markers used for PCa diagnosis, prognosis, and response to therapy are listed in Table 2.

It is well known that despite the fact that it is neither organ nor cancer specific, PSA is the most important, accurate, and clinically useful biochemical marker in the prostate [72-74]. As proved using IHC techniques, PSA expression is localized to the differentiated, secretory columnar cells of the glandular epithelium [75]. The apical portion of the epithelial cell cytoplasm shows more intense staining than the lower part, whereas the basal cells, transitional epithelium, or stromal cells do not express PSA. The PSA protein is strongly expressed, both in normal and neoplastic prostatic tissue; however, as evidenced by IHC staining, it is expressed less in cancer than in benign epithelium, and its expression decreases with the decreasing differentiation of PCa [76, 77]. Although IHC detection of PSA is still widely used to identify metastatic prostatic adenocarcinoma, PSA may not be expressed in some poorly differentiated prostatic carcinomas [78-80]. Its immunoreactivity has also been found in some nonprostatic tissues [81-83], making it useless, in such cases, for confirming prostatic origin.

Recently, novel marker proteins that are preferentially expressed in prostate tissue have been identified. Prostein 
TABle 2: Proteins as PCa biomarkers in FFPE tissue.

\begin{tabular}{|c|c|c|c|}
\hline Protein & Description & Clinical significance & References \\
\hline PSA & Prostate-specific antigen & Diagnosis (prostatic metastasis) & {$[84]$} \\
\hline P501S & Prostein & Diagnosis (prostatic metastasis) & {$[84,85]$} \\
\hline PSCA & Prostate stem cell antigen & $\begin{array}{l}\text { Diagnosis (incl. metastasis), prognosis } \\
(\uparrow)\end{array}$ & {$[86-88]$} \\
\hline AMACR/P504S & $\alpha$-methylacyl-CoA racemase & Diagnosis $(\uparrow)$ & {$[89-91,94,110,114]$} \\
\hline HMWCK & High-molecular-weight cytokeratin & Diagnosis $(\downarrow)$ & {$[101,103-105,110]$} \\
\hline ANXA3 & Annexin A3 & Prognosis $(\downarrow)$ & {$[166]$} \\
\hline $\mathrm{CgA}$ & Chromogranin A & Prognosis $(\uparrow)$, treatment outcome & {$[144-147]$} \\
\hline OPN & Osteopontin & Prognosis $(\uparrow)$ & [167] \\
\hline ZAG & Zinc-alpha 2-glycoprotein & Prognosis $(\downarrow)$ & {$[168,169]$} \\
\hline PSMA & Prostate-specific membrane antigen & Diagnosis, prognosis $(\uparrow)$ & {$[170,171]$} \\
\hline GOLPH2 & Golgi phosphoprotein 2 & Diagnosis $(\uparrow)$ & {$[99,100]$} \\
\hline GST-pi & Glutathione-S-transferase-pi & Diagnosis $(\downarrow)$ & {$[172]$} \\
\hline HPN & Hepsin & Diagnosis $(\uparrow)$ & {$[173,174]$} \\
\hline Maspin & Maspin protein/Serpin B5 & $\begin{array}{l}\text { Diagnosis }(\downarrow \text {, aberrant nuclear } \\
\text { distribution) }\end{array}$ & {$[172,175,176]$} \\
\hline MMP9 & Matrix metallopeptidase 9 & Prognosis $(\uparrow)$ & {$[177,178]$} \\
\hline PDEF/hPSE & Prostate-derived Ets transcription factor & Diagnosis, prognosis $(\downarrow)$ & {$[177,179,180]$} \\
\hline SPINK1/TATI & $\begin{array}{l}\text { Serine protease inhibitor Kazal-type } \\
\text { 1/Tumor-associated trypsin inhibitor }\end{array}$ & Diagnosis, prognosis $(\uparrow)$ & {$[181,182]$} \\
\hline Ki67 & Antigen KI-67 & Prognosis $(\uparrow)$, treatment outcome & {$[121,122,183]$} \\
\hline $\mathrm{B} 7-\mathrm{H} 3$ and $\mathrm{B} 7 \mathrm{x}$ & B7 family members & Prognosis $(\uparrow)$ & {$[131,133]$} \\
\hline p53 & Cellular tumor antigen p53 & Diagnosis $(\uparrow)$, treatment outcome & {$[134,135]$} \\
\hline p27 & Protein p27 & Prognosis $(\downarrow)$ & {$[184,185]$} \\
\hline p16 & Protein p16 & Prognosis $(\downarrow)$, treatment outcome & {$[186,187]$} \\
\hline uPA & Urokinase-type plasminogen activator & Prognosis $(\uparrow)$, treatment outcome & {$[188,189]$} \\
\hline MCT2 & Monocarboxylate transporter 2 & Diagnosis $(\uparrow)$ & [190] \\
\hline $\mathrm{AR}$ & Androgen receptor & Prognosis $(\downarrow)$, treatment outcome & {$[119,191]$} \\
\hline PTEN & Phosphatase and tensin homologue & Prognosis $(\downarrow)$, treatment outcome & {$[115,117-119,183]$} \\
\hline MSMB/PSP94 & $\beta$-Microseminoprotein/prostate secretory protein 94 & Prognosis $(\uparrow)$ & {$[192]$} \\
\hline $\mathrm{EZH} 2$ & Histone-lysine N-methyltransferase & Prognosis $(\uparrow)$ & {$[185,193]$} \\
\hline HSP27 & Heat shock $27 \mathrm{kDa}$ protein & Prognosis $(\uparrow)$ & {$[194,195]$} \\
\hline ErbB2/HER2 & Receptor tyrosine-protein kinase erbB-2 & Prognosis $(\uparrow)$ & {$[196,197]$} \\
\hline NKX3.1 & Homeobox protein Nkx-3.1 & Diagnosis (prostatic metastasis) & [198] \\
\hline $\mathrm{c}-\mathrm{Myc}$ & Myc protooncogene protein & Prognosis $(\uparrow)$, treatment outcome & {$[183,185]$} \\
\hline BIRC5 & Baculoviral IAP repeat-containing protein $5 /$ Survivin & Prognosis $(\downarrow)$ & {$[199,200]$} \\
\hline KLK4 & Kallikrein-4 & Prognosis $(\downarrow)$ & [201] \\
\hline TERT & Telomerase reverse transcriptase & Prognosis $(\uparrow)$, treatment outcome & {$[202,203]$} \\
\hline CRISP3 & Cysteine-rich secretory protein 3 & $\begin{array}{l}\text { Diagnosis, prognosis }(\uparrow) \text {, treatment } \\
\text { outcome }\end{array}$ & {$[95,204]$} \\
\hline BCL2 & Apoptosis regulator $\mathrm{Bcl}-2$ & Prognosis $(\uparrow)$, treatment outcome & [139-141] \\
\hline COX2 & Prostaglandin G/H synthase 2 & Treatment outcome & {$[124,128,130]$} \\
\hline VEGF-A & Vascular endothelial growth factor A & Prognosis $(\uparrow)$, treatment outcome & {$[205,206]$} \\
\hline HIF- $1 \alpha$ & Hypoxia-inducible factor 1-alpha & Treatment outcome & {$[207,208]$} \\
\hline
\end{tabular}

Arrows indicate the sense of deregulation: $(\uparrow)$ : upregulation; $(\downarrow)$ : downregulation in PCa versus normal tissues or low risk versus high risk PCa. 
(P501S), a prostate-specific marker that is expressed in the cytoplasm of benign and malignant prostatic glandular cells, is one of them. Owing to its high specificity and the fact that a large majority of metastatic prostatic adenocarcinomas are prostein positive (99\%), the combined use of P501S with PSA could be a good marker for demonstrating prostatic origin in metastatic PCa $[84,85]$.

Several studies using FFPE samples have shown that prostate stem cell antigen (PSCA), a prostate-specific gene, is expressed in most PCa specimens. Its levels are positively correlated with Gleason grade, tumor stage, progression to androgen-independence, and BCR and have also been found to be particularly elevated in bone metastasis [86-88]. All these data suggest that PSCA may be useful in prognosis and may be a promising molecular target in the diagnosis and treatment of patients with metastatic PCa. Another marker shown to be specifically increased in PCa epithelia, compared to benign epithelia, is $\alpha$-methylacyl-CoA racemase (AMACR or P504S) [89-91]. P504S is a PCa-specific gene that encodes a protein involved in the beta-oxidation of branched chain fatty acids. It is a sensitive and specific marker for prostatic carcinoma in FFPE tissues [92, 93]. Both high grade and low-grade PCa show strong cytoplasmic staining; however, a significant decrease in AMACR protein expression has been observed in cases of metastatic hormone-refractory disease compared with clinically localized PCa samples [94].

A useful IHC biomarker for PCa may be cysteine-rich secretory protein 3 (CRISP-3), also known as the specific granule protein of $28 \mathrm{kDa}$ (SGP28). CRISP-3 was found to be associated with high Gleason grade with elevated intensity, and it was also overexpressed in high-grade prostatic intraepithelial neoplasia (HG-PIN), which indicates that CRISP3 could be a marker for early cancer development [95, 96]. In addition, patients positive for CRISP-3 have smaller recurrence-free probabilities after RP [97]. Another proteinbased candidate for PCa diagnosis is Golgi membrane protein 1 (GOLM1, also known as GP73 and GOLPH2), a transmembrane protein expressed in the epithelial cells of many human tissues [98]. Several studies have recently reported the upregulation of this protein in malignant prostate tissue, suggesting GOLM1 as an additional ancillary positive marker for the tissue-based diagnosis of PCa $[99,100]$. On the other hand, PCa tissues, even those of high grade, only rarely express high-molecular-weight cytokeratin (HMWCK, sometimes also referred to as $34 \beta \mathrm{E} 12$, an anti-cytokeratin antibody, clone-specific for high-molecular-weight cytokeratins (cytokeratins 1, 5, 10, and 14)). That makes this marker a useful adjunct in the diagnosis of PCa [101, 102]. HMWCK immunoreactivity in benign glands is localized to the cytoplasm of basal cells and is negative in PCa. It is a particularly sensitive marker for the differentiation of $\mathrm{PCa}$ from high grade invasive urothelial carcinoma, where it can be detected by IHC [103-105]. Even though HMWCK labeling of PCa cells is uncommon, p63 has been reported to be even more specific than HMWCK as a marker for the basal cell nuclei of benign glands and with less tumor cell labeling [106].

The use of cocktails that include different antibodies as a routine test overcomes the problems of studying small lesions in prostate needle biopsies with multiple IHC stains $[107,108]$. For this reason, many studies have focused on attempting new combinations of markers that could improve the diagnostic process. For example, the overexpression of AMACR, in combination with the absence of basal cell markers, such as HMWCK or p63, is typical of classic acinar prostatic adenocarcinoma. Its detection has been shown to be of great value in combatting morphologically suspicious cases, as well as significantly increasing diagnostic accuracy in PCa [91, 109-112]. Furthermore, several studies have compared the usefulness of a three-marker cocktail of antibodies for detecting PCa. These cocktails incorporated AMACR (positive in malignant glands), p63 (nuclear staining in basal cells of nonmalignant glands), and HMWCK (cytoplasmic staining in basal cells of nonmalignant glands), along with the traditional two-marker cocktail. These studies all concluded that adding an extra basal cell marker to the traditional twoantibody cocktail significantly improved specificity for the detection of PCa in limited needle biopsy material $[107,113$, 114].

Phosphatase and tensin homolog on chromosome 10 (PTEN) has been described as one of the most frequently lost tumor suppressor genes in human cancers. Its expression is lost in more than two thirds of patients with advanced/aggressive PCa. Moreover, genomic and proteomic PTEN loss has been associated with tumor progression and poor prognosis in PCa [115-117]. In patients with clinically localized PCa, who were treated by RP, decreased PTEN expression has also been associated with an increased risk of recurrence and decreased time to metastasis [115, 118]. Choucair et al. [119] examined the deletion status of PTEN and the androgen receptor (AR) expression levels in FFPE PCa samples and found that PTEN genomic deletion predicts PCa recurrence. It was also associated with low AR expression and transcriptional activity.

Expression of the human Ki67 protein is known to be strictly associated with cell proliferation. The fraction of Ki67positive tumor cells (the Ki67 labeling index, Ki67 LI) is often in correlation with the clinical course of the disease, including cases of $\mathrm{PCa}$, where cell proliferation evaluated by Ki-67 increases from localized PCa to metastasis [54, 120]. A high Ki67 LI is independently associated with seminal vesicle infiltration and postoperative Gleason score. More importantly, the Ki67 LI can predict biochemical recurrence, particularly in the subgroup of patients with only a small amount of tumor in the biopsy. The Ki67 LI could also be a valid predictor of recurrence-free survival after radical prostatectomy $[121,122]$.

Cyclooxygenase-2 (COX-2) is also highly expressed in a number of human cancers and cancer cell lines, including $\mathrm{PCa}$ [123]. The potential roles of COX-2 in tumor related processes, such as tumorigenesis, angiogenesis [123-125], and radiation treatment resistance, make this an attractive biomarker candidate and potential therapeutic target [126129]. Increased COX-2 expression is associated with biochemical failure and distant metastasis; therefore, it could be useful in identifying patients who require more aggressive therapy [130]. 
Recently discovered members of the B7-CD28 family, B7$\mathrm{H} 3$, and B7x, were evaluated by IHC on pathological specimens from clinically localized PCa patients treated by RP $[131,132]$. These studies concluded that B7-H3 was uniformly and aberrantly expressed in PCa and correlated to the worst clinical outcomes of this disease [131]. Therefore, B7-H3 could represent an independent predictor of cancer progression following surgery. Moreover, B7-H3 may encompass a novel diagnostic and potentially therapeutic target for the clinical management of PCa [131]. Another IHC study performed on tissue microarray sections using anti-B7-H3 and anti-B7x corroborated that these proteins were abundantly expressed in PCa and were associated with the spread of disease and poor outcome [133].

It has been suggested that p53 accumulation or TP53 mutation could be used as both prognostic and predictive biomarkers. This is the most commonly mutated gene in human cancer and has been associated with poor prognosis in multiple and distinct types of cancer, including PCa [124, 134]. Abnormal p53 expression is a significant prognostic factor for patients with PCa, who have undergone short-term ADT and/or RT. It has also been suggested that long-term ADT may significantly improve the cause-specific survival for those with abnormal p53 [135]. Another biomarker associated with higher Gleason scores and lower biochemical-free survival in patients with advanced PCa undergoing ADT or RT is the gene product of the apoptosis regulator $\mathrm{Bcl}-2$. The relative amounts of $\mathrm{Bcl}-2$ and/or BAX, a proapoptotic protein from the same family, have been shown to correlate with tumor aggressiveness and radiation resistance in PCa [124, 136-138]. These data suggest that $\mathrm{Bcl}-2$ expression could be used to inform the choice of ADT or RT dosage in individual patients [139-141].

The RI-alpha regulatory subunit of protein kinase A type 1 (PKA) is associated with active cell growth and neoplastic transformation. Its overexpression has been found to be predictive of outcome in PCa patients treated with RT and shortterm ADT and is considered a potentially useful biomarker for identifying high risk PCa patients [142]. Another study from the same group showed that its overexpression was associated with an increased risk of failure after ADT and RT, suggesting that novel strategies may be needed for patients with tumors presenting high PKA levels $[124,143]$.

Most of the conventional prostate adenocarcinomas display focal neuroendocrine (NE) differentiation at diagnosis. The NE phenotype is emerging as an important factor in the evolution of $\mathrm{PCa}$, since it seems to be implicated in the development of resistance to ADT [144]. Chromogranin A (CgA) appears to be the most sensitive marker, and it is the most frequently used marker for detecting the NE phenotype by IHC [145]. It has a strong association with pathological tumor stage, since its expression levels are higher in poorly differentiated carcinomas. It has also been identified as an additional prognostic marker after RP $[146,147]$.

\section{Conclusions}

For a long time, PSA screening for PCa has been controversial. Although the PSA test is simple and safe and has an acceptable sensitivity and specificity, the implementation of PSA screening for PCa costs nearly double is associated with a high risk of overdiagnosis, and as a consequence presents the inevitable side effects that arise from unnecessary treatment [148]. The current method of definitive diagnosis for PCa typically relies on the morphological findings in the biopsied tissue, which, even for an experienced pathologist, can be difficult to classify. This method could be improved by using one or several molecular markers, which would help the pathologist to make the final diagnostic decision and differentiate between clinically significant and clinically insignificant disease. Thus, novel markers are required to improve the specificity of PCa diagnosis and to fully characterize the heterogeneity of prostate tumor phenotypes. These markers will more accurately assess the diagnosis and prognosis of patients with PCa [149]. This strategy would play an important role in achieving better patient management in the clinical practice. It would also assure a decrease in the number of repeat biopsies and faster identification of those patients who require more aggressive therapy. It is evident that there exists urgent need to identify better biomarkers for PCa presence, progression, and response to treatment, in order to avoid unnecessary overtreatment and accurately predict disease outcome.

Recently, several attempts have been made to identify novel biomarkers for $\mathrm{PCa}$, though the results were largely inconclusive [21]. However, several studies mentioned in this review have demonstrated that it is possible to find differentially expressed miRNAs and proteins that can distinguish between normal and malignant prostate tissues and can be used to classify and correctly diagnose even poorly differentiated tumor samples. Thus, both miRNA and protein expression profiles have potential as tools for the diagnosis and prognosis of cancer.

New technologies will be of great assistance in the application of these promising biomarkers to routine practice. An important challenge in cancer diagnostics will be to assay multiple parameters in a single slide when tissue quantities are limited. The development of multiplexed assays that maximize the yield of information from a small biopsy will help meet a critical challenge to current biomarker research. Accordingly, the implementation of ISH, in combination with IHC for the detection of clinically important miRNAs and protein markers in fixed specimens, now provides a fluorescence-based multicolor ISH/IHC assay. This assay is rapid, sensitive, and compatible with current automated clinical IHC assays and provides spatial characterization of miRNA expression [150,151]. Thanks to this combined ISH/IHC assay, miRNA and protein biomarkers can now be used together in detecting, classifying, diagnosing, prognosing, and treating cancer. For multiplexing protein panels Matrix-assisted laser desorption ionization (MALDI) imaging mass spectrometry (IMS) appears as a powerful tool for the generation of multidimensional spatial expression maps of biomolecules directly from a FFPE tissue section. From a clinical proteomics perspective, this method correlates molecular detail to histopathological changes found in patient-derived tissues. Targeted IMS, by the incorporation of laser-reactive molecular tags onto antibodies, aptamers, and 
other affinity molecules, enables analysis of specific molecules or a class of molecules. The integration of MALDI-IMS methods into existing clinical pathology laboratory practices could prove beneficial to diagnostics [152].

New strategies for the detection of PCa in biopsies material are also being developed. For example, a recent study described a new type of bioactive membrane vesicle (with the proposed name "large oncosomes") which can originate from tumor cells and is related to high Gleason grade and metastatic disease. They suggest that the detection of these pathological features could be adapted for routine histopathological analysis [153].

In this review, we have attempted to provide examples of potential miRNA and protein markers that have been discovered in prostate FFPE tissues, which may be of clinical benefit in PCa detection, prognosis, and/or prediction. Clearly, it would be beneficial to concentrate future efforts on the discovery and further study of the molecular mechanisms and regulatory pathways associated with PCa. This will help to improve the design and target selection of new therapeutic strategies. In summary, the development of novel and clinically relevant biomarkers in FFPE tissues for $\mathrm{PCa}$ diagnosis, prognosis, and prediction could contribute to the optimal identification and treatment of this disease.

\section{Authors' Contribution}

Tamara Sequeiros and Marta García contributed equally to this work.

\section{Acknowledgments}

The authors thank Movember Foundation, Instituto de Salud Carlos III: PI11/02486, CP10/00355, PS 09/00496, Ministerio de Ciéncia e Innovación: RTICC RD06/0036/0035, IPT-20111569-010000 y IPT-2012-1311-300000; Asociación Española Contra el Cáncer Junta Provincial de Barcelona: AECCJB-2011-03; Red de Genómica del Cáncer y Genotipado de tumores C03/10; and Fundación para la Investigación en Urología, Departament d'Univeristats, Recerca i Societat de la Informació de la Generalitat de Catalunya: SGR00487 and Lisa Piccione for reviewing the document.

\section{References}

[1] R. Siegel, D. Naishadham, and A. Jemal, "Cancer statistics, 2013," CA Cancer Journal for Clinicians, vol. 63, no. 1, pp. 11-30, 2013.

[2] M. J. Roobol, M. Kerkhof, F. H. Schröder et al., "Prostate cancer mortality reduction by prostate-specific antigen-based screening adjusted for nonattendance and contamination in the European Randomised Study of Screening for Prostate Cancer (ERSPC)," European Urology, vol. 56, no. 4, pp. 584-591, 2009.

[3] W. J. Catalona, M. A. Hudson, P. T. Scardino et al., "Selection of optimal prostate specific antigen cutoffs for early detection of prostate cancer: receiver operating characteristic curves," Journal of Urology, vol. 152, no. 6 I, pp. 2037-2042, 1994.

[4] A. Heidenreich, J. Bellmunt, M. Bolla et al., "EAU guidelines on prostate cancer. Part 1: screening, diagnosis, and treatment of clinically localised disease," European Urology, vol. 59, no. 1, pp. 61-71, 2011.

[5] A. V. D’Amico, R. Whittington, S. B. Malkowicz et al., "Pretreatment nomogram for prostate-specific antigen recurrence after radical prostatectomy or external-beam radiation therapy for clinically localized prostate cancer," Journal of Clinical Oncology, vol. 17, no. 1, pp. 168-172, 1999.

[6] C. Sumey and T. W. Flaig, "Adjuvant medical therapy for prostate cancer," Expert Opinion on Pharmacotherapy, vol. 12, no. 1, pp. 73-84, 2011.

[7] C. O. Madu and Y. Lu, "Novel diagnostic biomarkers for prostate cancer," Journal of Cancer, vol. 1, pp. 150-177, 2010.

[8] H. J. Issaq and T. D. Veenstra, Proteomic and Metabolomic Approaches to Biomarker Discovery, Academic Press, 2013.

[9] T. A. Dunn, H. Fedor, W. B. Isaacs, A. M. de Marzo, and J. Luo, "Genome-wide expression analysis of recently processed formalin-fixed paraffin embedded human prostate tissues," Prostate, vol. 69, no. 2, pp. 214-218, 2009.

[10] O. P. Kallioniemi, U. Wagner, J. Kononen, and G. Sauter, “Tissue microarray technology for high-throughput molecular profiling of cancer," Human Molecular Genetics, vol. 10, no. 7, pp. 657-662, 2001.

[11] I. Zlobec, V. H. Koelzer, H. Dawson, A. Perren, and A. Lugli, "Next-generation tissue microarray (ngTMA) increases the quality of biomarker studies: an example using CD3, CD8, and $\mathrm{CD} 45 \mathrm{RO}$ in the tumor microenvironment of six different solid tumor types," Journal of Translational Medicine, vol. 11, article 104, 2013.

[12] I. Zlobec, L. Terracciano, L. Tornillo et al., "Role of RHAMM within the hierarchy of well-established prognostic factors in colorectal cancer," Gut, vol. 57, no. 10, pp. 1413-1419, 2008.

[13] A. Aravin and T. Tuschl, "Identification and characterization of small RNAs involved in RNA silencing," FEBS Letters, vol. 579, no. 26, pp. 5830-5840, 2005.

[14] R. C. Lee, R. L. Feinbaum, and V. Ambros, "The C. elegans heterochronic gene lin- 4 encodes small RNAs with antisense complementarity to lin-14," Cell, vol. 75, no. 5, pp. 843-854, 1993.

[15] A. E. Pasquinelli, B. J. Reinhart, F. Slack et al., "Conservation of the sequence and temporal expression of let-7 heterochronic regulatory RNA," Nature, vol. 408, no. 6808, pp. 86-89, 2000.

[16] Y. Zhao and D. Srivastava, "A developmental view of microRNA function," Trends in Biochemical Sciences, vol. 32, no. 4, pp. 189197, 2007.

[17] V. Coppola, R. de Maria, and D. Bonci, "MicroRNAs and prostate cancer," Endocrine-Related Cancer, vol. 17, no. 1, pp. F1F17, 2010.

[18] O. Hassan, A. Ahmad, S. Sethi, and F. H. Sarkar, "Recent updates on the role of microRNAs in prostate cancer," Journal of Hematology and Oncology, vol. 5, article 9, 2012.

[19] G. A. Calin, C. Sevignani, C. D. Dumitru et al., "Human microRNA genes are frequently located at fragile sites and genomic regions involved in cancers," Proceedings of the National Academy of Sciences of the United States of America, vol. 101, no. 9, pp. 2999-3004, 2004.

[20] S. Pollari, S. K. Leivonen, Perälä et al., "Identification of microRNAs inhibiting TGF- $\beta$-induced IL-11 production in bone metastatic breast cancer cells," PLOS ONE, vol. 7, no. 5, Article ID e37361, 2012.

[21] J. Carlsson, S. Davidsson, G. Helenius et al., "A miRNA expression signature that separates between normal and malignant prostate tissues," Cancer Cell International, vol. 11, article 14, 2011. 
[22] B. P. Lewis, C. B. Burge, and D. P. Bartel, "Conserved seed pairing, often flanked by adenosines, indicates that thousands of human genes are microRNA targets," Cell, vol. 120, no. 1, pp. 15-20, 2005.

[23] N. Rajewsky, "microRNA target predictions in animals," Nature Genetics, vol. 38, no. 1, pp. S8-S13, 2006.

[24] Y. Pang, C. Y. F. Young, and H. Yuan, "MicroRNAs and prostate cancer," Acta Biochimica et Biophysica Sinica, vol. 42, no. 6, pp. 363-369, 2010.

[25] X. B. Shi, L. Xue, J. Yang et al., "An androgen-regulated miRNA suppresses Bak1 expression and induces androgen-independent growth of prostate cancer cells," Proceedings of the National Academy of Sciences of the United States of America, vol. 104, no. 50, pp. 19983-19988, 2007.

[26] X. Li, Y. T. Chen, S. Josson et al., "MicroRNA-185 and 342 inhibit tumorigenicity and induce apoptosis through blockade of the SREBP metabolic pathway in prostate cancer cells," PLOS ONE, vol. 8, no. 8, Article ID e70987, 2013.

[27] M. D. Mattie, C. C. Benz, J. Bowers et al., "Optimized highthroughput microRNA expression profiling provides novel biomarker assessment of clinical prostate and breast cancer biopsies," Molecular Cancer, vol. 5, article 24, 2006.

[28] K. P. Porkka, M. J. Pfeiffer, K. K. Waltering, R. L. Vessella, T. L. J. Tammela, and T. Visakorpi, "MicroRNA expression profiling in prostate cancer," Cancer Research, vol. 67, no. 13, pp. 6130-6135, 2007.

[29] J. B. Munding, A. T. Adai, A. Maghnouj et al., "Global microRNA expression profiling of microdissected tissues identifies miR-135b as a novel biomarker for pancreatic ductal adenocarcinoma," International Journal of Cancer, vol. 131, no. 2, pp. E86-E95, 2012.

[30] A. E. Szafranska, T. S. Davison, J. Shingara et al., "Accurate molecular characterization of formalin-fixed, paraffinembedded tissues by microRNA expression profiling," Journal of Molecular Diagnostics, vol. 10, no. 5, pp. 415-423, 2008.

[31] B. Hasemeier, M. Christgen, H. Kreipe, and U. Lehmann, "Reliable microRNA profiling in routinely processed formalin-fixed paraffin-embedded breast cancer specimens using fluorescence labelled bead technology," BMC Biotechnology, vol. 8, article 90, 2008.

[32] P. S. Mitchell, R. K. Parkin, E. M. Kroh et al., "Circulating microRNAs as stable blood-based markers for cancer detection," Proceedings of the National Academy of Sciences of the United States of America, vol. 105, no. 30, pp. 10513-10518, 2008.

[33] J. S. Jang, V. A. Simon, R. M. Feddersen et al., "Quantitative miRNA expression analysis using fluidigm microfluidics dynamic arrays," BMC Genomics, vol. 12, article 144, 2011.

[34] Y. Xi, G. Nakajima, E. Gavin et al., "Systematic analysis of microRNA expression of RNA extracted from fresh frozen and formalin-fixed paraffin-embedded samples," RNA, vol. 13, no. 10, pp. 1668-1674, 2007.

[35] D. de Biase, M. Visani, L. Morandi et al., "miRNAs expression analysis in paired fresh/Frozen and dissected formalin fixed and paraffin embedded glioblastoma using real-time PCR," PLoS ONE, vol. 7, no. 4, Article ID e35596, 2012.

[36] K. R. M. Leite, J. M. S. Canavez, S. T. Reis et al., "MiRNA analysis of prostate cancer by quantitative real time PCR: comparison between formalin-fixed paraffin embedded and fresh-frozen tissue," Urologic Oncology, vol. 29, no. 5, pp. 533-537, 2011.

[37] J. R. Dijkstra, L. J. M. Mekenkamp, S. Teerenstra, I. de Krijger, and I. D. Nagtegaal, "MicroRNA expression in formalin-fixed paraffin embedded tissue using real time quantitative PCR: the strengths and pitfalls," Journal of Cellular and Molecular Medicine, vol. 16, pp. 683-690, 2012.

[38] J. Lu, G. Getz, E. A. Miska et al., "MicroRNA expression profiles classify human cancers," Nature, vol. 435, no. 7043, pp. 834-838, 2005.

[39] S. Ambs, R. L. Prueitt, M. Yi et al., "Genomic profiling of microRNA and messenger RNA reveals deregulated microRNA expression in prostate cancer," Cancer Research, vol. 68, no. 15, pp. 6162-6170, 2008.

[40] M. Ozen, C. J. Creighton, M. Ozdemir, and M. Ittmann, "Widespread deregulation of microRNA expression in human prostate cancer," Oncogene, vol. 27, no. 12, pp. 1788-1793, 2008.

[41] L. Nonn, A. Vaishnav, L. Gallagher, and P. H. Gann, "mRNA and micro-RNA expression analysis in laser-capture microdissected prostate biopsies: valuable tool for risk assessment and prevention trials," Experimental and Molecular Pathology, vol. 88, no. 1, pp. 45-51, 2010.

[42] J. Szczyrba, E. Löprich, S. Wach et al., "The microRNA profile of prostate carcinoma obtained by deep sequencing," Molecular Cancer Research, vol. 8, no. 4, pp. 529-538, 2010.

[43] S. Wach, E. Nolte, J. Szczyrba et al., "MicroRNA profiles of prostate carcinoma detected by multiplatform microRNA screening," International Journal of Cancer, vol. 130, no. 3, pp. 611-621, 2012.

[44] S. Sethi, D. Kong, S. Land, G. Dyson, W. A. Sakr, and F. H. Sarkar, "Comprehensive molecular oncogenomic profiling and miRNA analysis of prostate cancer," American Journal of Translational Research, vol. 5, no. 2, pp. 200-211, 2013.

[45] M. Schubert, M. Spahn, S. Kneitz et al., "Distinct microRNA expression profile in prostate cancer patients with early clinical failure and the impact of let-7 as prognostic marker in highrisk prostate cancer," PLoS ONE, vol. 8, no. 6, Article ID e65064, 2013.

[46] K. R. M. Leite, J. M. Sousa-Canavez, S. T. Reis et al., "Change in expression of miR-let7c, miR-100, and miR-218 from high grade localized prostate cancer to metastasis," Urologic Oncology, vol. 29, no. 3, pp. 265-269, 2011.

[47] M. Z. Michael, S. M. O’Connor, N. G. Van Holst Pellekaan, G. P. Young, and R. J. James, "Reduced accumulation of specific microRNAs in colorectal neoplasia," Molecular Cancer Research, vol. 1, no. 12, pp. 882-891, 2003.

[48] N. Yanaihara, N. Caplen, E. Bowman et al., "Unique microRNA molecular profiles in lung cancer diagnosis and prognosis," Cancer Cell, vol. 9, no. 3, pp. 189-198, 2006.

[49] S. O. Suh, Y. Chen, M. S. Zaman et al., "MicroRNA-145 is regulated by DNA methylation and p53 gene mutation in prostate cancer," Carcinogenesis, vol. 32, no. 5, pp. 772-778, 2011.

[50] X. Chen, J. Gong, H. Zeng et al., "MicroRNA145 targets BNIP3 and suppresses prostate cancer progression," Cancer Research, vol. 70, no. 7, pp. 2728-2738, 2010.

[51] X. Peng, W. Guo, T. Liu et al., "Identification of miRs-143 and -145 that is associated with bone metastasis of prostate cancer and involved in the regulation of EMT," PLOS ONE, vol. 6, no. 5, Article ID e20341, 2011.

[52] D. Kong, E. Heath, W. Chen et al., "Loss of let-7 up-regulates EZH2 in prostate cancer consistent with the acquisition of cancer stem cell signatures that are attenuated by BR-DIM," PLoS ONE, vol. 7, no. 3, Article ID e33729, 2012.

[53] S. M. Johnson, H. Grosshans, J. Shingara et al., "RAS is regulated by the let-7 microRNA family," Cell, vol. 120, no. 5, pp. 635-647, 2005. 
[54] S. T. Reis, L. S. Timoszczuk, J. Pontes-Junior et al., "The role of micro RNAs let7c, 100 and 218 expression and their target RAS, C-MYC, BUB1, RB, SMARCA5, LAMB3 and Ki-67 in prostate cancer," Clinics, vol. 68, no. 5, pp. 652-657, 2013.

[55] M. Spahn, S. Kneitz, C. J. Scholz et al., "Expression of microRNA-221 is progressively reduced in aggressive prostate cancer and metastasis and predicts clinical recurrence," International Journal of Cancer, vol. 127, no. 2, pp. 394-403, 2010.

[56] N. Barron, J. Keenan, P. Gammell et al., "Biochemical relapse following radical prostatectomy and miR-200a levels in prostate cancer," Prostate, vol. 72, no. 11, pp. 1193-1199, 2012.

[57] B. A. Walter, V. A. Valera, P. A. Pinto, and M. J. Merino, "Comprehensive microRNA profiling of prostate cancer," Journal of Cancer, vol. 4, no. 5, pp. 350-357, 2013.

[58] Y. Liu, Y. Han, H. Zhang et al., "Synthetic miRNA-mowers targeting miR-183-96-182 cluster or miR-210 inhibit growth and migration and induce apoptosis in bladder cancer cells," PLoS ONE, vol. 7, no. 12, Article ID e52280, 2012.

[59] B. L. Mihelich, E. A. Khramtsova, N. Arva et al., "miR-183-96182 cluster is overexpressed in prostate tissue and regulates zinc homeostasis in prostate cells," Journal of Biological Chemistry, vol. 286, no. 52, pp. 44503-44511, 2011.

[60] A. Schaefer, M. Jung, H. J. Mollenkopf et al., "Diagnostic and prognostic implications of microRNA profiling in prostate carcinoma," International Journal of Cancer, vol. 126, no. 5, pp. 1166-1176, 2010.

[61] M. F. Segura, D. Hanniford, S. Menendez et al., "Aberrant miR182 expression promotes melanoma metastasis by repressing FOXO3 and microphthalmia-associated transcription factor," Proceedings of the National Academy of Sciences of the United States of America, vol. 106, no. 6, pp. 1814-1819, 2009.

[62] I. K. Guttilla and B. A. White, "Coordinate regulation of FOXO1 by miR-27a, miR-96, and miR-182 in breast cancer cells," Journal of Biological Chemistry, vol. 284, no. 35, pp. 23204-23216, 2009.

[63] L. Jiang, P. Mao, L. Song et al., "miR-182 as a prognostic marker for glioma progression and patient survival," American Journal of Pathology, vol. 177, no. 1, pp. 29-38, 2010.

[64] Z. Liu, J. Liu, M. F. Segura et al., "MiR-182 overexpression in tumourigenesis of high-grade serous ovarian carcinoma," Journal of Pathology, vol. 228, no. 2, pp. 204-215, 2012.

[65] H. Hirata, K. Ueno, V. Shahryari et al., "MicroRNA-182-5p promotes cell invasion and proliferation by down regulating FOXF2, RECK and MTSS1 genes in human prostate cancer," PLoS ONE, vol. 8, no. 1, Article ID e55502, 2013.

[66] K. Tsuchiyama, H. Ito, M. Taga et al., "Expression of microRNAs associated with Gleason grading system in prostate cancer: miR-182-5p is a useful marker for high grade prostate cancer," Prostate, vol. 73, no. 8, pp. 827-834, 2013.

[67] Q. Long, B. A. Johnson, A. O. Osunkoya et al., "Proteincoding and microRNA biomarkers of recurrence of prostate cancer following radical prostatectomy," American Journal of Pathology, vol. 179, no. 1, pp. 46-54, 2011.

[68] A. Bjartell, R. Montironi, D. M. Berney, and L. Egevad, “Tumour markers in prostate cancer II: diagnostic and prognostic cellular biomarkers," Acta Oncologica, vol. 50, no. 1, pp. 76-84, 2011.

[69] H. Guo, W. Liu, Z. Ju et al., "An efficient procedure for protein extraction from formalin-fixed, paraffin-embedded tissues for reverse phase protein arrays," Proteome Science, vol. 10, article 56, no. 1, 2012.

[70] J. A. Ramos-Vara, "Technical aspects of immunohistochemistry," Veterinary Pathology, vol. 42, no. 4, pp. 405-426, 2005.
[71] D. Robertson, K. Savage, J. S. Reis-Filho, and C. M. Isacke, "Multiple immunofluorescence labelling of formalin-fixed paraffinembedded (FFPE) tissue," BMC Cell Biology, vol. 9, article 13, 2008.

[72] D. G. Bostwick, "Prostate-specific antigen: current role in diagnostic pathology of prostate cancer," American Journal of Clinical Pathology, vol. 102, no. 4, pp. S31-S37, 1994.

[73] R. J. Ablin, "A retrospective and prospective overview of prostate-specific antigen," Journal of Cancer Research and Clinical Oncology, vol. 123, no. 11-12, pp. 583-594, 1997.

[74] A. Haese, M. Graefen, T. Steuber et al., "Human glandular kallikrein 2 levels in serum for discrimination of pathologically organ-confined from locally-advanced prostate cancer in total PSA-levels below 10 ng/ml," Prostate, vol. 49, no. 2, pp. 101-109, 2001.

[75] D. M. Peehl, "Prostate specific antigen role and function," Cancer, vol. 75, no. 7, pp. 2021-2026, 1995.

[76] M. F. Darson, A. Pacelli, P. Roche et al., "Human glandular kallikrein 2 (hK2) expression in prostatic intraepithelial neoplasia and adenocarcinoma: a novel prostate cancer marker," Urology, vol. 49, no. 6, pp. 857-862, 1997.

[77] U. H. Stenman, J. Leinonen, W. M. Zhang, and P. Finne, "Prostate-specific antigen," Seminars in Cancer Biology, vol. 9, no. 2, pp. 83-93, 1999.

[78] M. P. W. Gallee, E. Visser-De Jong, J. A. G. M. van der Korput et al., "Variation of prostate-specific antigen expression in different tumour growth patterns present in prostatectomy specimens," Urological Research, vol. 18, no. 3, pp. 181-187, 1990.

[79] M. P. Roudier, L. D. True, C. S. Higano et al., "Phenotypic heterogeneity of end-stage prostate carcinoma metastatic to bone," Human Pathology, vol. 34, no. 7, pp. 646-653, 2003.

[80] A. A. Renshaw and S. R. Granter, "Metastatic, sarcomatoid, and PSA- and PAP-negative prostatic carcinoma: diagnosis by fineneedle aspiration," Diagnostic Cytopathology, vol. 23, no. 3, pp. 199-201, 2000.

[81] P. J. Carder, V. Speirs, J. Ramsdale, and M. R. J. Lansdown, "Expression of prostate specific antigen in male breast cancer," Journal of Clinical Pathology, vol. 58, no. 1, pp. 69-71, 2005.

[82] A. A. A. Elgamal, N. L. Ectors, S. Sunardhi-Widyaputra, H. P. Van Poppel, B. J. Van Damme, and L. V. Baert, "Detection of prostate specific antigen in pancreas and salivary glands: a potential impact on prostate cancer overestimation," Journal of Urology, vol. 156, no. 2, pp. 464-468, 1996.

[83] G. F. Holmes, D. W. Eisele, D. Rosenthal, and W. H. Westra, "PSA immunoreactivity in a parotid oncocytoma: a diagnostic pitfall in discriminating primary parotid neoplasms from metastatic prostate cancer," Diagnostic Cytopathology, vol. 19, pp. 221-225, 1998.

[84] T. Sheridan, M. Herawi, J. I. Epstein, and P. B. Illei, "The role of P501S and PSA in the diagnosis of metastatic adenocarcinoma of the prostate," American Journal of Surgical Pathology, vol. 31, no. 9, pp. 1351-1355, 2007.

[85] M. Yin, R. Dhir, and A. V. Parwani, "Diagnostic utility of p501s (prostein) in comparison to prostate specific antigen (PSA) for the detection of metastatic prostatic adenocarcinoma," Diagnostic Pathology, vol. 2, no. 1, article 41, 2007.

[86] Z. Gu, G. Thomas, J. Yamashiro et al., "Prostate stem cell antigen (PSCA) expression increases with high gleason score, advanced stage and bone metastasis in prostate cancer," Oncogene, vol. 19, no. 10, pp. 1288-1296, 2000. 
[87] J. S. Lam, J. Yamashiro, I. P. Shintaku et al., "Prostate stem cell antigen is overexpressed in prostate cancer metastases," Clinical Cancer Research, vol. 11, no. 7, pp. 2591-2596, 2005.

[88] Z. Zhigang and S. Wenlv, "Prostate stem cell antigen (PSCA) expression in human prostate cancer tissues and its potential role in prostate carcinogenesis and progression of prostate cancer," World Journal of Surgical Oncology, vol. 2, article 13, 2004.

[89] M. Zhou, Z. Jiang, and J. I. Epstein, "Expression and diagnostic utility of alpha-methylacyl-CoA-racemase (P504S) in foamy gland and pseudohyperplastic prostate cancer," American Journal of Surgical Pathology, vol. 27, no. 6, pp. 772-778, 2003.

[90] I. Leav, J. E. McNeal, S. M. Ho, and Z. Jiang, " $\alpha$-Methylacyl-CoA racemase (P504S) expression in evolving carcinomas within benign prostatic hyperplasia and in cancers of the transition zone," Human Pathology, vol. 34, no. 3, pp. 228-233, 2003.

[91] J. Luo, S. Zha, W. R. Gage et al., " $\alpha$-methylacyl-CoA racemase: a new molecular marker for prostate cancer," Cancer Research, vol. 62, no. 8, pp. 2220-2226, 2002.

[92] R. Beach, A. M. Gown, M. N. de Peralta-Venturina et al., "P504S immunohistochemical detection in 405 prostatic specimens including 376 18-gauge needle biopsies," American Journal of Surgical Pathology, vol. 26, no. 12, pp. 1588-1596, 2002.

[93] Z. Jiang, B. A. Woda, K. L. Rock et al., "P504S: a new molecular marker for the detection of prostate carcinoma," American Journal of Surgical Pathology, vol. 25, no. 11, pp. 1397-1404, 2001.

[94] M. A. Rubin, M. Zhou, S. M. Dhanasekaran et al., " $\alpha$-methylacyl coenzyme A racemase as a tissue biomarker for prostate cancer," Journal of the American Medical Association, vol. 287, no. 13, pp. 1662-1670, 2002.

[95] A. Bjartell, R. Johansson, T. Björk et al., "Immunohistochemical detection of cysteine-rich secretory protein 3 in tissue and in serum from men with cancer or benign enlargement of the prostate gland," Prostate, vol. 66, no. 6, pp. 591-603, 2006.

[96] F. Kosari, Y. W. Asmann, J. C. Cheville, and G. Vasmatzis, "Cysteine-rich secretory protein-3: a potential biomarker for prostate cancer," Cancer Epidemiology Biomarkers and Prevention, vol. 11, no. 11, pp. 1419-1426, 2002.

[97] A. S. Bjartell, H. Al-Ahmadie, A. M. Serio et al., "Association of cysteine-rich secretory protein 3 and $\beta$-microseminoprotein with outcome after radical prostatectomy," Clinical Cancer Research, vol. 13, no. 14, pp. 4130-4138, 2007.

[98] H. J. Kim, D. Lv, Y. Zhang, T. Peng, and X. Ma, "Golgi phosphoprotein 2 in physiology and in diseases," Cell \& Bioscience, vol. 2, no. 1, article 31, 2012.

[99] G. Kristiansen, F. R. Fritzsche, K. Wassermann et al., "GOLPH2 protein expression as a novel tissue biomarker for prostate cancer: implications for tissue-based diagnostics," British Journal of Cancer, vol. 99, no. 6, pp. 939-948, 2008.

[100] S. Varambally, B. Laxman, R. Mehra et al., "Golgi protein GOLM1 is a tissue and urine biomarker of prostate cancer," Neoplasia, vol. 10, no. 11, pp. 1285-1294, 2008.

[101] X. J. Yang, K. Lecksell, P. Gaudin, and J. I. Epstein, "Rare expression of high-molecular-weight cytokeratin in adenocarcinoma of the prostate gland. A study of 100 cases of metastatic and locally advanced prostate cancer," American Journal of Surgical Pathology, vol. 23, no. 2, pp. 147-152, 1999.

[102] S. I. Aishima, Y. Asayama, K. I. Taguchi et al., "The utility of keratin 903 as a new prognostic marker in mass-forming-type intrahepatic cholangiocarcinoma," Modern Pathology, vol. 15, no. 11, pp. 1181-1190, 2002.
[103] A. Y. Chuang, A. M. DeMarzo, R. W. Veltri, R. B. Sharma, C. J. Bieberich, and J. I. Epstein, "Immunohistochemical differentiation of high-grade prostate carcinoma from urothelial carcinoma," American Journal of Surgical Pathology, vol. 31, no. 8, pp. 1246-1255, 2007.

[104] M. Varma, M. Morgan, M. B. Amin, S. Wozniak, and B. Jasani, "High molecular weight cytokeratin antibody (clone $34 \beta \mathrm{E} 12$ ): a sensitive marker for differentiation of high-grade invasive urothelial carcinoma from prostate cancer," Histopathology, vol. 42, no. 2, pp. 167-172, 2003.

[105] L. P. Kunju, R. Mehra, M. Snyder, and R. B. Shah, "Prostatespecific antigen, high-molecular-weight cytokeratin (clone 34 $\beta$ E12), and/or p63: an optimal immunohistochemical panel to distinguish poorly differentiated prostate adenocarcinoma from urothelial carcinoma," American Journal of Clinical Pathology, vol. 125, no. 5, pp. 675-681, 2006.

[106] T. Z. Ali and J. I. Epstein, "False positive labeling of prostate cancer with high molecular weight cytokeratin: P63 a more specific immunomarker for basal cells," American Journal of Surgical Pathology, vol. 32, no. 12, pp. 1890-1895, 2008.

[107] Z. Jiang, C. Li, A. Fischer, K. Dresser, and B. A. Woda, "Using an AMACR (P504S)/34 $\beta$ E12/p63 cocktail for the detection of small focal prostate carcinoma in needle biopsy specimens," American Journal of Clinical Pathology, vol. 123, no. 2, pp. 231236, 2005.

[108] D. E. Tacha and R. T. Miller, "Use of p63/P504S monoclonal antibody cocktail in immunohistochemical staining of prostate tissue," Applied Immunohistochemistry and Molecular Morphology, vol. 12, no. 1, pp. 75-78, 2004.

[109] M. Herawi and J. I. Epstein, "Immunohistochemical antibody cocktail staining (p63/HMWCK/AMACR) of ductal adenocarcinoma and Gleason pattern 4 cribriform and noncribriform acinar adenocarcinomas of the prostate," American Journal of Surgical Pathology, vol. 31, no. 6, pp. 889-894, 2007.

[110] K. Kumaresan, N. Kakkar, A. Verma, A. K. Mandal, S. K. Singh, and K. Joshi, "Diagnostic utility of $\alpha$-methylacyl CoA racemase (P504S) \& HMWCK in morphologically difficult prostate cancer," Diagnostic Pathology, vol. 5, no. 1, article 83, 2010.

[111] M. Zhou, R. Shah, R. Shen, and M. A. Rubin, "Basal cell cocktail $(34 \beta \mathrm{E} 12+\mathrm{p} 63)$ improves the detection of prostate basal cells," American Journal of Surgical Pathology, vol. 27, no. 3, pp. 365371, 2003.

[112] C. Boran, E. Kandirali, F. Yilmaz, E. Serin, and M. Akyol, "Reliability of the $34 \beta \mathrm{E} 12$, keratin 5/6, p63, bcl-2, and AMACR in the diagnosis of prostate carcinoma," Urologic Oncology, vol. 29, no. 6, pp. 614-623, 2011.

[113] P. D. Dabir, P. Ottosen, S. Høyer, and S. Hamilton-Dutoit, "Comparative analysis of three- and two-antibody cocktails to AMACR and basal cell markers for the immunohistochemical diagnosis of prostate carcinoma," Diagnostic Pathology, vol. 7, article 81, 2012.

[114] V. W. L. Ng, M. Koh, S. Y. Tan, and P. H. Tan, "Is triple immunostaining with $34 \beta \mathrm{E} 12, \mathrm{p} 63$, and racemase in prostate cancer advantageous? A tissue microarray study," American Journal of Clinical Pathology, vol. 127, no. 2, pp. 248-253, 2007.

[115] A. Chaux, S. B. Peskoe, N. Gonzalez-Roibon et al., "Loss of PTEN expression is associated with increased risk of recurrence after prostatectomy for clinically localized prostate cancer," Modern Pathology, vol. 25, pp. 1543-1549, 2012.

[116] H. Beltran, R. Yelensky, G. M. Frampton et al., "Targeted nextgeneration sequencing of advanced prostate cancer identifies 
potential therapeutic targets and disease heterogeneity," European Urology, vol. 63, no. 5, pp. 920-926, 2013.

[117] J. Cuzick, Z. H. Yang, G. Fisher et al., "Prognostic value of PTEN loss in men with conservatively managed localised prostate cancer," British Journal of Cancer, vol. 108, no. 12, pp. 2582-2589, 2013.

[118] T. L. Lotan, B. Gurel, S. Sutcliffe et al., "PTEN protein loss by immunostaining: analytic validation and prognostic indicator for a high risk surgical cohort of prostate cancer patients," Clinical Cancer Research, vol. 17, no. 20, pp. 6563-6573, 2011.

[119] K. Choucair, J. Ejdelman, F. Brimo, A. Aprikian, S. Chevalier, and J. Lapointe, "PTEN genomic deletion predicts prostate cancer recurrence and is associated with low $\mathrm{AR}$ expression and transcriptional activity," BMC Cancer, vol. 12, article 543, 2012.

[120] T. Scholzen and J. Gerdes, "The Ki-67 protein: from the known and the unknown," Journal of Cellular Physiology2000, vol. 182, no. 3, pp. 311-322.

[121] S. H. Madani, S. Ameli, S. Khazaei, M. Kanani, and B. Izadi, "Frequency of Ki-67 (MIB-1) and P53 expressions among patients with prostate cancer," Indian Journal of Pathology and Microbiology, vol. 54, no. 4, pp. 688-691, 2011.

[122] T. Zellweger, S. Günther, I. Zlobec et al., "Tumour growth fraction measured by immunohistochemical staining of Ki67 is an independent prognostic factor in preoperative prostate biopsies with small-volume or low-grade prostate cancer," International Journal of Cancer, vol. 124, no. 9, pp. 2116-2123, 2009.

[123] A. Kirschenbaum, X. H. Liu, S. Yao, and A. C. Levine, "The role of cyclooxygenase-2 in prostate cancer," Urology, vol. 58, no. 2, pp. 127-131, 2001.

[124] P. T. Tran, R. K. Hales, J. Zeng et al., "Tissue biomarkers for prostate cancer radiation therapy," Current Molecular Medicine, vol. 12 , no. 6 , pp. 772-787, 2012.

[125] J. L. Masferrer, K. M. Leahy, A. T. Koki et al., "Antiangiogenic and antitumor activities of cyclooxygenase-2 inhibitors," Cancer Research, vol. 60, no. 5, pp. 1306-1311, 2000.

[126] R. S. Pruthi, J. E. Derksen, D. Moore et al., "Phase II trial of celecoxib in prostate-specific antigen recurrent prostate cancer after definitive radiation therapy or radical prostatectomy," Clinical Cancer Research, vol. 12, no. 7, pp. 2172-2177, 2006.

[127] B. Wen, E. Deutsch, P. Eschwege et al., "Cyclooxygenase-2 inhibitor NS398 enhances antitumor effect of irradiation on hormone refractory human prostate carcinoma cells," Journal of Urology, vol. 170, no. 5, pp. 2036-2039, 2003.

[128] S. T. Palayoor, M. J. Arayankalayil, A. Shoaibi, and C. Norman Coleman, "Radiation sensitivity of human carcinoma cells transfected with small interfering RNA targeted against cyclooxygenase-2," Clinical Cancer Research, vol. 11, no. 19, pp. 6980-6986, 2005.

[129] E. Nakata, K. A. Mason, N. Hunter et al., "Potentiation of tumor response to radiation or chemoradiation by selective cyclooxygenase-2 enzyme inhibitors," International Journal of Radiation Oncology Biology Physics, vol. 58, no. 2, pp. 369-375, 2004.

[130] L. Y. Khor, K. Bae, A. Pollack et al., "COX-2 expression predicts prostate-cancer outcome: analysis of data from the RTOG 92-02 trial," Lancet Oncology, vol. 8, no. 10, pp. 912-920, 2007.

[131] T. J. Roth, Y. Sheinin, C. M. Lohse et al., "B7-H3 ligand expression by prostate cancer: a novel marker of prognosis and potential target for therapy," Cancer Research, vol. 67, no. 16, pp. 7893-7900, 2007.
[132] G. Chavin, Y. Sheinin, P. L. Crispen et al., "Expression of immunosuppresive B7-H3 ligand by hormone-treated prostate cancer tumors and metastases," Clinical Cancer Research, vol. 15, no. 6, pp. 2174-2180, 2009.

[133] X. Zang, R. H. Thompson, H. A. Al-Ahmadie et al., "B7-H3 and B7x are highly expressed in human prostate cancer and associated with disease spread and poor outcome," Proceedings of the National Academy of Sciences of the United States of America, vol. 104, no. 49, pp. 19458-19463, 2007.

[134] P. J. Vlachostergios, F. Karasavvidou, A. Patrikidou et al., "p53 and cyclooxygenase-2 expression are directly associated with cyclin D1 expression in radical prostatectomy specimens of patients with hormone-naïve prostate cancer," Pathology and Oncology Research, vol. 18, no. 2, pp. 245-252, 2012.

[135] M. Che, M. DeSilvio, A. Pollack et al., "Prognostic value of abnormal p53 expression in locally advanced prostate cancer treated with androgen deprivation and radiotherapy: a study based on RTOG 9202," International Journal of Radiation Oncology Biology Physics, vol. 69, no. 4, pp. 1117-1123, 2007.

[136] D. S. Scherr, E. D. Vaughan Jr., J. Wei et al., "bcl-2 and p53 expression in clinically localized prostate cancer predicts response to external beam radiotherapy," Journal of Urology, vol. 162, no. 1, pp. 12-17, 1999.

[137] M. Tsuji, Y. Murakami, H. Kanayama, T. Sano, and S. Kagawa, "Immunohistochemical analysis of Ki-67 antigen and Bcl-2 protein expression in prostate cancer: effect of neoadjuvant hormonal therapy," British Journal of Urology, vol. 81, no. 1, pp. 116-121, 1998.

[138] A. Bylund, P. Stattin, A. Widmark, and A. Bergh, "Predictive value of bcl-2 immunoreactivity in prostate cancer patients treated with radiotherapy," Radiotherapy and Oncology, vol. 49, no. 2, pp. 143-148, 1998.

[139] K. Anvari, M. S. Toussi, M. Kalantari et al., "Expression of Bcl-2 and Bax in advanced or metastatic prostate carcinoma," Urology Journal, vol. 9, no. 1, pp. 381-388, 2012.

[140] L. Y. Khor, J. Moughan, T. Al-Saleem et al., "Bcl-2 and bax expression predict prostate cancer outcome in men treated with androgen deprivation and radiotherapy on radiation therapy oncology group protocol 92-02," Clinical Cancer Research, vol. 13, no. 12, pp. 3585-3590, 2007.

[141] R. Vergis, C. M. Corbishley, K. Thomas et al., "Expression of Bcl-2, p53, and MDM2 in localized prostate cancer with respect to the outcome of radical radiotherapy dose escalation," International Journal of Radiation Oncology Biology Physics, vol. 78, no. 1, pp. 35-41, 2010.

[142] L. Y. Khor, K. Bae, T. Al-Saleem et al., "Protein kinase A RI$\alpha$ predicts for prostate cancer outcome: analysis of radiation therapy oncology group trial 86-10," International Journal of Radiation Oncology Biology Physics, vol. 71, no. 5, pp. 1309-1315, 2008.

[143] A. Pollack, K. Bae, L. Y. Khor et al., "The importance of protein kinase A in prostate cancer: relationship to patient outcome in Radiation Therapy Oncology Group trial 92-02," Clinical Cancer Research, vol. 15, no. 17, pp. 5478-5484, 2009.

[144] A. Berruti, E. Bollito, C. M. Cracco et al., "The prognostic role of immunohistochemical chromogranin A expressionin prostate cancer patients is significantly modified by androgendeprivation therapy," Prostate, vol. 70, no. 7, pp. 718-726, 2010.

[145] A. Mosca, A. Berruti, L. Russo, M. Torta, and L. Dogliotti, "The neuroendocrine phenotype in prostate cancer: basic and clinical aspects," Journal of endocrinological investigation, vol. 28, no. 11, pp. 141-145, 2005. 
[146] M. H. Ather, F. Abbas, N. Faruqui, M. Israr, and S. Pervez, "Correlation of three immunohistochemically detected markers of neuroendocrine differentiation with clinical predictors of disease progression in prostate cancer," BMC Urology, vol. 8, no. 1, article 21, 2008.

[147] M. May, M. Siegsmund, F. Hammermann, V. Loy, and S. Gunia, "Prognostic significance of proliferation activity and neuroendocrine differentiation to predict treatment failure after radical prostatectomy," Scandinavian Journal of Urology and Nephrology, vol. 41, no. 5, pp. 375-381, 2007.

[148] E. A. M. Heijnsdijk, A. Der Kinderen, E. M. Wever, G. Draisma, M. J. Roobol, and H. J. de Koning, "Overdetection, overtreatment and costs in prostate-specific antigen screening for prostate cancer," British Journal of Cancer, vol. 101, no. 11, pp. 1833-1838, 2009.

[149] G. Sardana, B. Dowell, and E. P. Diamandis, "Emerging biomarkers for the diagnosis and prognosis of prostate cancer," Clinical Chemistry, vol. 54, no. 12, pp. 1951-1960, 2008.

[150] L. F. Sempere, M. Preis, T. Yezefski et al., "Fluorescence-based codetection with protein markers reveals distinct cellular compartments for altered microRNA expression in solid tumors," Clinical Cancer Research, vol. 16, no. 16, pp. 4246-4255, 2010.

[151] B. S. Nielsen, T. Moller, and K. Holmstrom, "Abstract LB-480: MicroRNA in situ hybridization techniques: co-detection of target protein and image analysis-based quantitation," Cancer Research, vol. 72, no. 8, supplement 1, Article ID LB-480, 2012.

[152] L. H. Cazares, D. A. Troyer, B. Wang, R. R. Drake, and O. John Semmes, "MALDI tissue imaging: from biomarker discovery to clinical applications," Analytical and Bioanalytical Chemistry, vol. 401, no. 1, pp. 17-27, 2011.

[153] D. Di Vizio, M. Morello, A. C. Dudley et al., "Large oncosomes in human prostate cancer tissues and in the circulation of mice with metastatic disease," American Journal of Pathology, vol. 181, no. 5, pp. 1573-1584, 2012.

[154] D. F. Liu, J. T. Wu, J. M. Wang, Q. Z. Liu, Z. L. Gao, and Y. X. Liu, "MicroRNA expression profile analysis reveals diagnostic biomarker for human prostate cancer," The Asian Pacific Journal of Cancer Prevention, vol. 13, no. 7, pp. 3313-3317, 2012.

[155] X. Zhang, A. Ladd, E. Dragoescu, W. T. Budd, J. L. Ware, and Z. E. Zehner, "MicroRNA-17-3p is a prostate tumor suppressor in vitro and in vivo, and is decreased in high grade prostate tumors analyzed by laser capture microdissection," Clinical and Experimental Metastasis, vol. 26, no. 8, pp. 965-979, 2009.

[156] J. Carlsson, G. Helenius, M. G. Karlsson, O. Andrén et al., "Differences in microRNA expression during tumor development in the transition and peripheral zones of the prostate," $B M C$ Cancer, vol. 13, article 362, 2013.

[157] T. Li, R. S. Li, Y. H. Li et al., "MiR-21 as an independent biochemical recurrence predictor and potential therapeutic target for prostate cancer," Journal of Urology, vol. 187, no. 4, pp. 1466-1472, 2012.

[158] Y. Li, D. Kong, A. Ahmad, B. Bao, G. Dyson, and F. H. Sarkar, "Epigenetic deregulation of miR-29a and miR-1256 by isoflavone contributes to the inhibition of prostate cancer cell growth and invasion," Epigenetics, vol. 7, no. 8, pp. 940-949, 2012.

[159] P. Ru, R. Steele, P. Newhall, N. J. Phillips, K. Toth, and R. B. Ray, "miRNA-29b suppresses prostate cancer metastasis by regulating epithelial-mesenchymal transition signaling," Molecular Cancer Therapeutics, vol. 11, no. 5, pp. 1166-1173, 2012.

[160] S. Yamamura, S. Saini, S. Majid et al., "Microrna-34a modulates c-Myc transcriptional complexes to suppress malignancy in human prostate cancer cells," PLoS ONE, vol. 7, no. 1, Article ID e29722, 2012.

[161] A. Formosa, A. M. Lena, E. K. Markert et al., "DNA methylation silences miR-132 in prostate cancer," Oncogene, vol. 32, no. 1, pp. 127-134, 2012.

[162] W. Guo, D. Ren, X. Chen et al., "HEF1 promotes epithelial mesenchymal transition and bone invasion in prostate cancer under the regulation of microRNA-145," Journal of Cellular Biochemistry, vol. 114, pp. 1606-1615, 2013.

[163] Y. G. Man, S. W. Fu, A. J. Liu et al., "Aberrant expression of chromogranin A, miR-146a, and miR-146b-5p in prostate structures with focally disrupted basal cell layers: an early sign of invasion and hormone-refractory cancer?" Cancer Genomics and Proteomics, vol. 8, no. 5, pp. 235-244, 2011.

[164] G. Viticchiè, A. M. Lena, A. Latina et al., "MiR-203 controls proliferation, migration and invasive potential of prostate cancer cell lines," Cell Cycle, vol. 10, no. 7, pp. 1121-1131, 2011.

[165] S. Ma, Y. P. Chan, P. S. Kwan et al., "MicroRNA-616 induces androgen-independent growth of prostate cancer cells by suppressing expression of tissue factor pathway inhibitor TFPI-2," Cancer Research, vol. 71, no. 2, pp. 583-592, 2011.

[166] J. Köllermann, T. Schlomm, H. Bang et al., "Expression and Prognostic Relevance of Annexin A3 in Prostate Cancer," European Urology, vol. 54, no. 6, pp. 1314-1323, 2008.

[167] S. S. Forootan, C. S. Foster, V. R. Aachi et al., "Prognostic significance of osteopontin expression in human prostate cancer," International Journal of Cancer, vol. 118, no. 9, pp. 2255-2261, 2006.

[168] A. Descazeaud, A. de La Taille, Y. Allory et al., "Characterization of ZAG protein expression in prostate cancer using a semiautomated microscope system," Prostate, vol. 66, no. 10, pp. 1037-1043, 2006.

[169] P. Y. Yip, J. G. Kench, K. K. Rasiah et al., "Low AZGP1 expression predicts for recurrence in margin-positive, localized prostate cancer," Prostate, vol. 71, no. 15, pp. 1638-1645, 2011.

[170] S. Minner, C. Wittmer, M. Graefen et al., "High level PSMA expression is associated with early psa recurrence in surgically treated prostate cancer," Prostate, vol. 71, no. 3, pp. 281-288, 2011.

[171] G. L. Wright, C. Haley, M. L. Beckett, and P. F. Schellhammer, "Expression of prostate-specific membrane antigen in normal, benign, and malignant prostate tissues," Urologic Oncology, vol. 1, no. 1, pp. 18-28, 1995.

[172] E. Lovrić, Z. Gatalica, E. Eyzaguirre, and B. Krušlin, "Expression of maspin and glutathionine-S-transferase- $\pi$ in normal human prostate and prostatic carcinomas," Applied Immunohistochemistry and Molecular Morphology, vol. 18, no. 5, pp. 429-432, 2010.

[173] M. Goel, D. Agrawal, S. Natu, and A. Goel, "Hepsin immunohistochemical expression in prostate cancer in relation to Gleason's grade and serum prostate specific antigen," Indian Journal of Pathology and Microbiology, vol. 54, no. 3, pp. 476-481, 2011.

[174] G. Pace, R. Pomante, and C. Vicentini, "Hepsin in the diagnosis of prostate cancer," MinErva Urologica E NEfrologica, vol. 4, pp. 143-148, 2012.

[175] S. Machtens, J. Serth, C. Bokemeyer et al., "Expression of the p53 and Maspin protein in primary prostate cancer: correlation with clinical features," International Journal of Cancer, vol. 95, no. 5, pp. 337-342, 2001.

[176] Z. Chen, Z. Fan, J. E. McNeal et al., "Hepsin and maspin are inversely expressed in laser capture microdissectioned prostate cancer," Journal of Urology, vol. 169, no. 4, pp. 1316-1319, 2003. 
[177] T. R. Johnson, S. Koul, B. Kumar et al., "Loss of PDEF, a prostatederived Ets factor is associated with aggressive phenotype of prostate cancer: regulation of MMP 9 by PDEF," Molecular Cancer, vol. 9, article 148, 2010.

[178] L. Zhang, J. Shi, J. Feng, H. Klocker, C. Lee, and J. Zhang, “Type IV collagenase (matrix metalloproteinase-2 and -9) in prostate cancer," Prostate Cancer and Prostatic Diseases, vol. 7, no. 4, pp. 327-332, 2004.

[179] A. Ghadersohi, S. Sharma, S. Zhang et al., "Prostate-derived Ets transcription factor (PDEF) is a potential prognostic marker in patients with prostate cancer," Prostate, vol. 71, no. 11, pp. 1178$1188,2011$.

[180] Y. Tsujimoto, N. Nonomura, H. Takayama et al., "Utility of immunohistochemical detection of prostate-specific Ets for the diagnosis of benign and malignant prostatic epithelial lesions," International Journal of Urology, vol. 9, no. 3, pp. 167-172, 2002.

[181] A. Paju, K. Hotakainen, Y. Cao et al., "Increased expression of tumor-associated trypsin inhibitor, TATI, in prostate cancer and in androgen-independent 22Rv1 cells," European Urology, vol. 52, no. 6, pp. 1670-1681, 2007.

[182] K. A. Leinonen, T. T. Tolonen, H. Bracken et al., "Association of SPINK1 expression and TMPRSS2:ERG fusion with prognosis in endocrine-treated prostate cancer," Clinical Cancer Research, vol. 16, no. 10, pp. 2845-2851, 2010.

[183] E. S. Antonarakis, D. Keizman, Z. Zhang et al., "An immunohistochemical signature comprising PTEN, MYC, and Ki67 predicts progression in prostate cancer patients receiving adjuvant docetaxel after prostatectomy," Cancer, vol. 118, no. 24, pp. 60636071, 2012.

[184] R. M. Yang, J. Naitoh, M. Murphy et al., "Low p27 expression predicts poor disease-free survival in patients with prostate cancer," Journal of Urology, vol. 159, no. 3, pp. 941-945, 1998.

[185] K. Li, M. Chen, J. Situ et al., "Role of co-expression of c-Myc, EZH2 and p27 in prognosis of prostate cancer patients after surgery," Chinese Medical Journal, vol. 126, no. 1, pp. 82-87, 2013.

[186] S. C. Kudahetti, G. Fisher, L. Ambroisine et al., "Immunohistochemistry for $\mathrm{p} 16$, but not $\mathrm{Rb}$ or $\mathrm{p} 21$, is an independent predictor of prognosis in conservatively treated, clinically localised prostate cancer," Pathology, vol. 42, no. 6, pp. 519-523, 2010.

[187] A. Chakravarti, M. DeSilvio, M. Zhang et al., "Prognostic value of p16 in locally advanced prostate cancer: a study based on Radiation Therapy Oncology Group protocol 9202," Journal of Clinical Oncology, vol. 25, no. 21, pp. 3082-3089, 2007.

[188] M. Kumano, H. Miyake, M. Muramaki, J. Furukawa, A. Takenaka, and M. Fujisawa, "Expression of urokinase-type plasminogen activator system in prostate cancer: correlation with clinicopathological outcomes in patients undergoing radical prostatectomy," Urologic Oncology, vol. 27, no. 2, pp. 180-186, 2009.

[189] C. Thomas, C. Wiesner, S. W. Melchior et al., "Urokinaseplasminogen-activator receptor expression in disseminated tumour cells in the bone marrow and peripheral blood of patients with clinically localized prostate cancer," BJU International, vol. 104, no. 1, pp. 29-34, 2009.

[190] N. Pértega-Gomes, J. R. Vizcaíno, C. Gouveia et al., "Monocarboxylate transporter 2 (MCT2) as putative biomarker in prostate cancer," Prostate, vol. 73, no. 3, pp. 763-769, 2013.

[191] X. Zhang, C. Morrissey, S. Sun et al., "Androgen receptor variants occur frequently in castration resistant prostate cancer metastases," PLoS ONE, vol. 6, no. 11, Article ID e27970, 2011.

[192] A. R. Girvan, P. Chang, I. Van Huizen et al., "Increased intratumoral expression of prostate secretory protein of 94 amino acids predicts for worse disease recurrence and progression after radical prostatectomy in patients with prostate cancer," Urology, vol. 65, no. 4, pp. 719-723, 2005.

[193] S. Laitinen, P. M. Martikainen, T. Tolonen, J. Isola, T. L. J. Tammela, and T. Visakorpi, "EZH2, Ki-67 and MCM7 are prognostic markers in prostatectomy treated patients," International Journal of Cancer, vol. 122, no. 3, pp. 595-602, 2008.

[194] P. A. Cornford, A. R. Dodson, K. F. Parsons et al., "Heat shock protein expression independently predicts clinical outcome in prostate cancer," Cancer Research, vol. 60, no. 24, pp. 7099-7105, 2000.

[195] C. S. Foster, A. R. Dodson, L. Ambroisine et al., "Hsp27 expression at diagnosis predicts poor clinical outcome in prostate cancer independent of ETS-gene rearrangement," British Journal of Cancer, vol. 101, no. 7, pp. 1137-1144, 2009.

[196] S. Minner, B. Jessen, L. Stiedenroth et al., "Low level Her2 overexpression is associated with rapid tumor cell proliferation and poor prognosis in prostate cancer," Clinical Cancer Research, vol. 16, no. 5, pp. 1553-1560, 2010.

[197] Y. Yamada, K. Nakamura, S. Aoki et al., "An immunohistochemical study of chromogranin A and human epidermal growth factor-2 expression using initial prostate biopsy specimens from patients with bone metastatic prostate cancer," BJU International, vol. 99, no. 1, pp. 189-195, 2007.

[198] B. Gurel, T. Z. Ali, E. A. Montgomery et al., "NKX3.1 as a marker of prostatic origin in metastatic tumors," American Journal of Surgical Pathology, vol. 34, no. 8, pp. 1097-1105, 2010.

[199] S. F. Shariat, Y. Lotan, H. Saboorian et al., "Survivin expression is associated with features of biologically aggressive prostate carcinoma," Cancer, vol. 100, no. 4, pp. 751-757, 2004.

[200] M. Zhang, A. Ho, E. H. Hammond et al., "Prognostic value of survivin in locally advanced prostate cancer: study based on RTOG 8610," International Journal of Radiation Oncology Biology Physics, vol. 73, no. 4, pp. 1033-1042, 2009.

[201] L. Seiz, M. Kotzsch, N. I. Grebenchtchikov et al., "Polyclonal antibodies against kallikrein-related peptidase 4 (KLK4): immunohistochemical assessment of KLK4 expression in healthy tissues and prostate cancer," Biological Chemistry, vol. 391, no. 4, pp. 391-401, 2010.

[202] K. A. Iczkowski, C. G. Pantazis, D. H. McGregor, Y. Wu, and O. W. Tawfik, "Telomerase reverse transcriptase subunit immunoreactivity: a marker for high-grade prostate carcinoma," Cancer, vol. 95, no. 12, pp. 2487-2493, 2002.

[203] J. Tang, Z. Wang, X. Li, J. Li, and H. Shi, "Human telomerase reverse transcriptase expression correlates with vascular endothelial growth factor-promoted tumor cell proliferation in prostate cancer," Artificial Cells, Blood Substitutes, and Biotechnology, vol. 36, no. 2, pp. 83-93, 2008.

[204] A. S. Bjartell, H. Al-Ahmadie, A. M. Serio et al., "Association of cysteine-rich secretory protein 3 and $\beta$-microseminoprotein with outcome after radical prostatectomy," Clinical Cancer Research, vol. 13, no. 14, pp. 4130-4138, 2007.

[205] K. Gyftopoulos, K. Vourda, G. Sakellaropoulos, P. Perimenis, A. Athanasopoulos, and E. Papadaki, "The angiogenic switch for vascular endothelial growth factor-a and cyclooxygenase2 in prostate carcinoma: correlation with microvessel density, androgen receptor content and Gleason grade," Urologia Internationalis, vol. 87, no. 4, pp. 464-469, 2011.

[206] T. T. Tomiá, H. Gustavsson, W. Wang, K. Jennbacken, K. Welén, and J. E. Damber, "Castration resistant prostate cancer is associated with increased blood vessel stabilization and elevated 
levels of VEGF and Ang-2," Prostate, vol. 72, no. 7, pp. 705-712, 2012.

[207] D. C. Weber, J. C. Tille, C. Combescure et al., "The prognostic value of expression of HIF1 $\alpha$, EGFR and VEGF-A, in localized prostate cancer for intermediate- and high-risk patients treated with radiation therapy with or without androgen deprivation therapy," Results Radiation Oncology, vol. 7, article 66, 2012.

[208] W. K. B. Ranasinghe, L. Xiao, S. Kovac et al., "The role of hypoxia-inducible factor $1 \alpha$ in determining the properties of castrate-resistant prostate cancers," PLOS ONE, vol. 8, no. 1, Article ID e54251, 2013. 


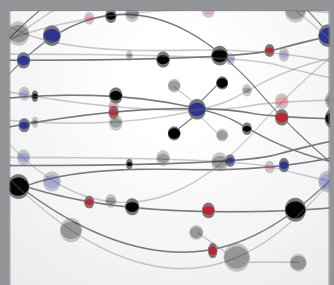

The Scientific World Journal
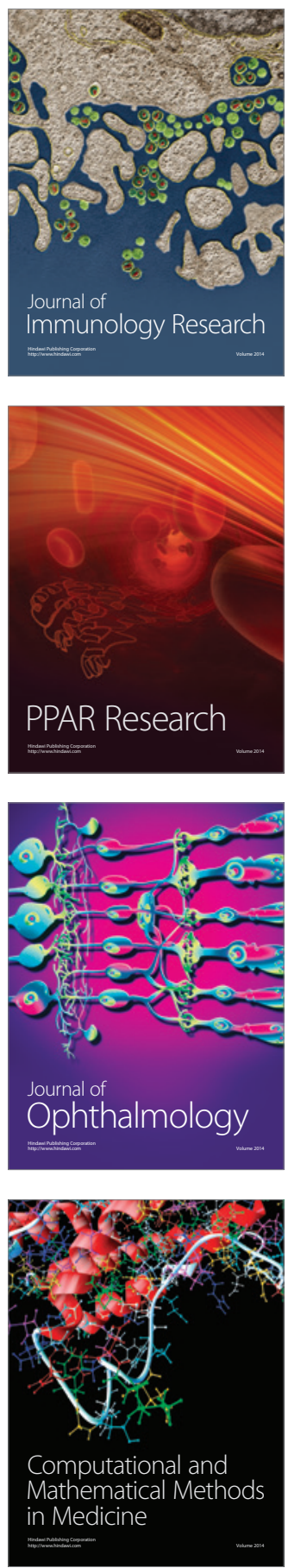

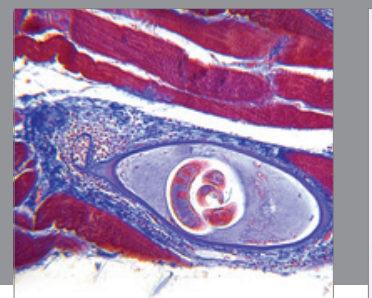

Gastroenterology

Research and Practice
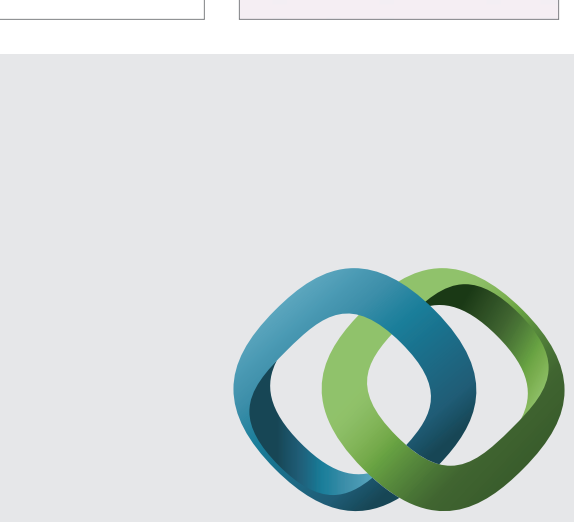

\section{Hindawi}

Submit your manuscripts at

http://www.hindawi.com
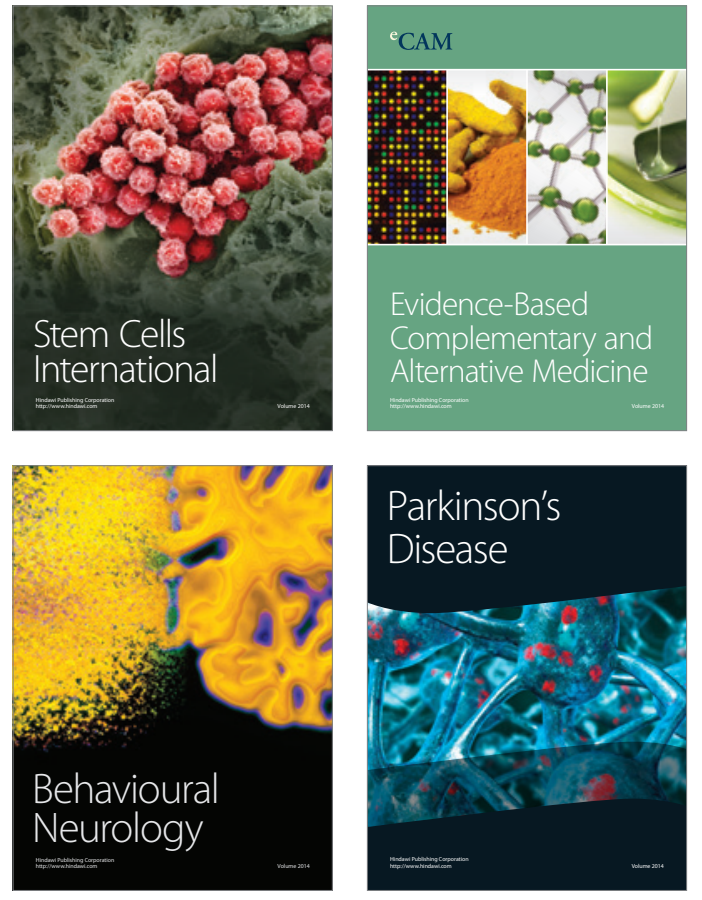
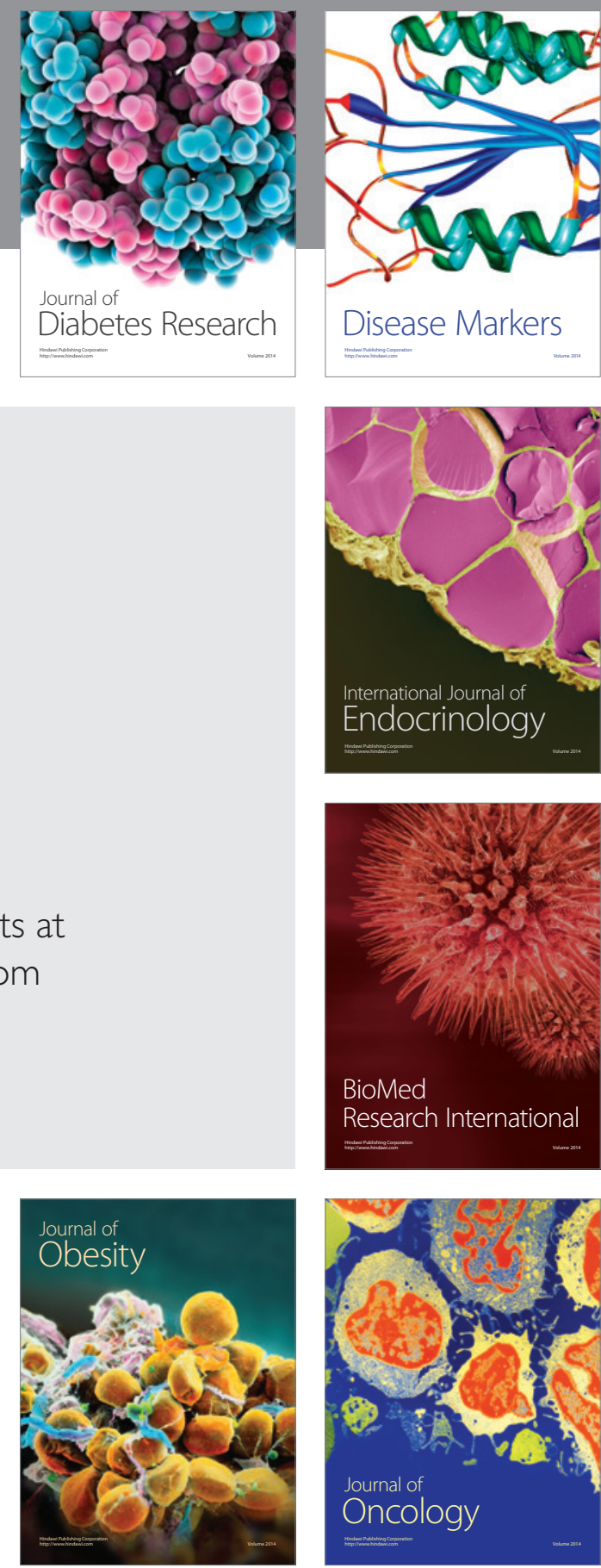

Disease Markers
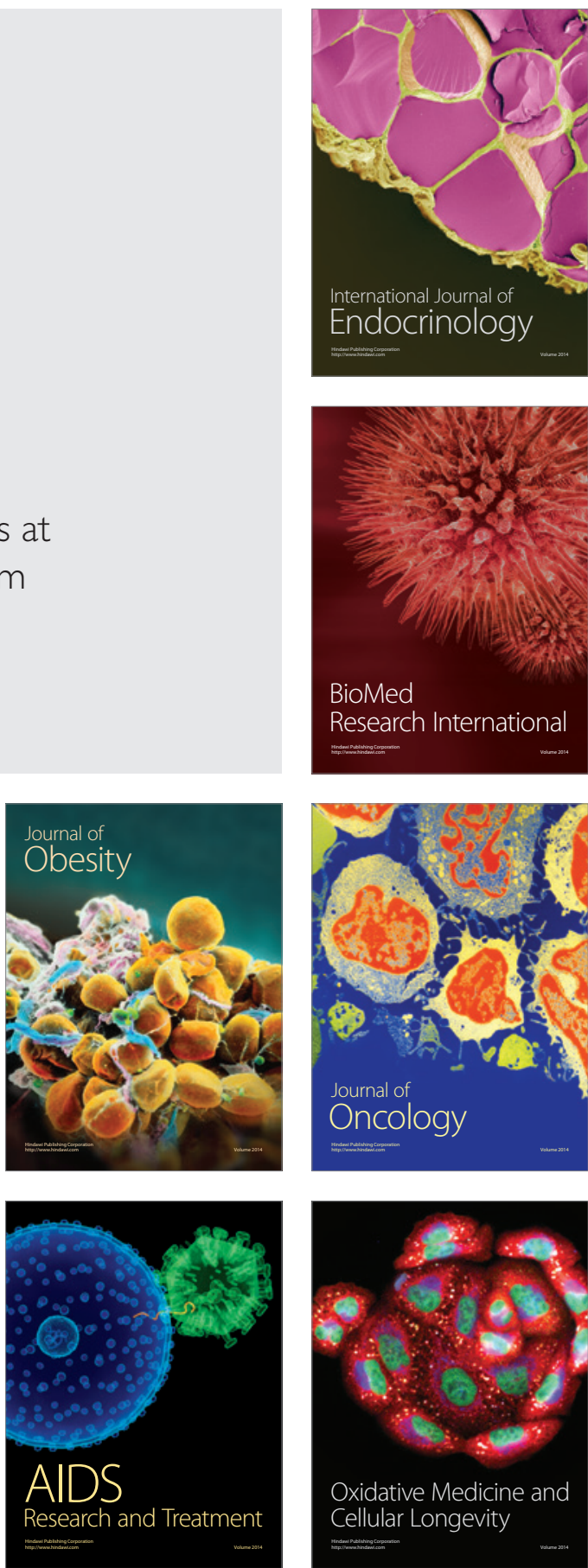